\title{
RAP1 regulates TIP60 function during fate transition between 2 cell-like and pluripotent states
}

Raymond Mario Barry ${ }^{1,2}$, Olivia Sacco ${ }^{2}$, Amel Mameri ${ }^{3}$, Martin Stojaspal ${ }^{1,4}$, William Kartsonis ${ }^{1}$, Pooja Shah ${ }^{1}$, Pablo De loannes ${ }^{5}$, Ctirad Hofr ${ }^{4,6}$, Jacques Côté ${ }^{3}$, and Agnel Sfeir ${ }^{*}$

1- Skirball Institute of Biomolecular Medicine, Department of Cell Biology, NYU School of Medicine, New York, NY 10016, USA

2- Molecular Biology Program, Sloan Kettering Institute, Memorial Sloan Kettering Cancer Center, New York, NY 10065, USA

3- $\quad$ St-Patrick Research Group in Basic Oncology; CHU de Québec-Université Laval Research Center-Oncology Division; Laval University Cancer Research Center, Quebec City, QC G1R 3S3, Canada

4- $\quad$ LifeB, Functional Genomics and Proteomics, National Centre for Biomolecular Research, Faculty of Science, Masaryk University, Brno, Czech Republic

5- Skirball Institute of Biomolecular Medicine, Department of Biochemistry and Molecular Pharmacology, NYU School of Medicine, New York, NY 10016, USA 6- Institute of Biophysics of the Czech Academy of Sciences, Scientific Incubator, Královopolská 135, 61265 Brno, Czech Republic

${ }^{*}$ Correspondence to SfeirA@mskcc.org

Keywords: RAP1, telomere, TIP60, EPC1, 2C-like, ZSCAN4, MERVL 


\section{Summary:}

In mammals, the conserved telomere binding protein RAP1 serves a diverse set of nontelomeric functions including activation of the NF-kB signaling pathway, maintenance of metabolic function in vivo, and transcriptional regulation. Here, we uncover the mechanism by which RAP1 modulates gene expression. Using a separation-of-function allele, we show that RAP1 transcriptional regulation is independent of TRF2-mediated binding to telomeres and does not involve direct binding to genomic loci. Instead, RAP1 interacts with the TIP60/p400 complex and modulates its histone acetyltransferase activity. Notably, we show that deletion of RAP1 in mouse embryonic stem cells increases the fraction of 2-cell-like cells. Specifically, RAP1 enhances the repressive activity of Tip60/p400 across a subset of 2-cell-stage genes, including Zscan4 and the endogenous retrovirus MERVL. Preferential upregulation of genes proximal to MERVL elements in Rap1 deficient settings implicate these endogenous retroviral elements in the derepression of proximal genes. Altogether, our study reveals an unprecedented link between RAP1 and TIP60/p400 complex in the regulation of totipotency. 


\section{Introduction}

Rap1 (Repressor/ Activator Protein 1) was first identified in Saccharomyces cerevisiae (S. cerevisiae) as a transcription factor that silences the alternate silent matingtype loci and maintains high transcriptional activity at genes encoding ribosomal proteins and glycolytic enzymes (Huet et al. 1985; Huet and Sentenac 1987; Shore and Nasmyth 1987; Shore et al. 1987; Vignais et al. 1987; Chambers et al. 1989). Subsequent studies found yeast Rap1 to be a primary telomere DNA binding protein that maintains proper telomere length, ensures subtelomere silencing, and inhibits telomere end-end fusions (Berman et al. 1986; Buchman et al. 1988a; Buchman et al. 1988b; Longtine et al. 1989; Lustig et al. 1990; Kyrion et al. 1993; Pardo and Marcand 2005). Upon senescence of budding yeast, Rap1 is evicted from telomeres and relocalizes to promoter targets, including histone-encoding genes (Platt et al. 2013; Song et al. 2020). In Schizosaccharomyces pombe (S. pombe), Rap1 performs a similar protective function at telomeres, albeit, it relies on a protein-protein interaction with Taz1 to be recruited to chromosome ends (Kanoh and Ishikawa 2001).

Mammalian RAP1, encoded by TERF2IP, is a component of shelterin, a sixsubunit protein complex that is additionally composed of TRF1, TRF2, TIN2, POT1, and TPP1. Shelterin coats mammalian telomere DNA and prevents the activation of DNA damage signaling and repair at chromosome ends (de Lange 2005; Lazzerini-Denchi and Sfeir 2016). Whereas budding yeast Rap1 binds telomeric DNA directly using two tandem Myb domains, mammalian RAP1 comprises a single Myb domain and relies on a stable interaction with TRF2 to be recruited to TTAGGG-bearing telomere DNA (Li et al. 2000; Hanaoka et al. 2001). RAP1 function at telomeres diverged from yeast as revealed by 
genetic studies showing that deletion of mammalian RAP1 is largely dispensable for telomere end-protection. Whereas loss of all other shelterin components is incompatible with life, Rap1 knockout (Rap1/-) mice are alive, fertile and display no premature aging phenotypes (Karlseder et al. 2003; Chiang et al. 2004; Celli and de Lange 2005; Hockemeyer et al. 2006; Kibe et al. 2010; Sfeir et al. 2010). Loss of function analysis indicated that RAP1 is dispensable for chromosome-end protection. However, in certain experimental settings, it was found to act with TRF2 to suppress NHEJ mediated telomere fusions (Sarthy et al. 2009; Kabir et al. 2014; Lototska et al. 2020). Furthermore, in the absence of Ku70/80, telomere sister-chromatic exchanges are induced upon Rap1 depletion, implicating a redundant role for RAP1 in suppression of telomere recombination (Sfeir et al. 2010; Rai et al. 2016).

Analysis of $\mathrm{Rap1}^{-/}$mice in vivo and ex vivo shed light into the function of mammalian Rap1 in regulating gene expression (Martinez et al. 2010; Teo et al. 2010; Martinez et al. 2013; Yeung et al. 2013). At the organismal level, Rap1 deficiency leads to glucose intolerance, dyslipidemia, liver steatosis, and excess fat accumulation, ultimately manifesting as late-onset obesity. Rap $1^{-/-}$mice exhibit altered gene expression in a subset of tissues and prior to the onset of obesity. Furthermore, mouse embryonic fibroblasts (MEFs) from Rap1\% embryos display dysregulated gene expression, a phenotype rescued by exogenous expression of Rap1, indicating that Rap1 regulates gene expression in a cell-autonomous manner (Martinez et al. 2013; Yeung et al. 2013). These observations point to an extratelomeric function of RAP1 in regulating gene expression; however, the mechanistic basis of this regulation remains elusive. 
Regulation of gene expression is orchestrated by a complex interplay of transcription factors and chromatin regulators, including chromatin remodelers, histone chaperones, and epigenetic modifiers that write/erase histone post-translational modifications . Histone acetylation is one such modification that regulates the structure of chromatin and typically leads to activation of gene expression (Workman and Abmayr 2014). Histone acetyltransferase (HAT) complexes tend to be large and multimeric, such as the highly conserved TIP60/p400 complex, also known as NuA4. TIP60/p400 is composed of $>18$ subunits including the lysine acetyltransferase (KAT) catalytic subunit Tip60 (KAT5), two scaffold proteins p400 (Ep400) and Trrap, Epc1/2, Dmap1 and Ing3 (Doyon and Cote 2004). TIP60/p400 plays a role in a diverse set of biological processes including transcription, cell proliferation, and DNA repair by homologous recombination (Steunou et al. 2014; Jacquet et al. 2016; Sheikh and Akhtar 2019). TIP60/p400 regulates transcription through acetylation of histones $\mathrm{H} 4$ and $\mathrm{H} 2 \mathrm{~A}$ catalyzed by the TIP60 subunit, but can also modulate gene expression by incorporation of the histone variant H2A.Z using the ATP-dependent chromatin remodeling activity of Ep400 (Allard et al. 1999; Pradhan et al. 2016). TIP60/p400 is also necessary for proper maintenance and renewal of stem cells (Fazzio et al. 2008; Acharya et al. 2017). Specifically, this HAT complex was recently found to suppress emergence of 2-cell-like (2C-like) cells, a small population of cells in mouse embryonic stem cell (mESC) cultures that share characteristics with twocell stage embryos including expression of endogenous retroviral MERVL elements and enhanced totipotent potential (Rodriguez-Terrones et al. 2018). Paradoxically, TIP60/p400 increases totipotency by repressing a subset of $2 \mathrm{C}$ genes, however, the 
underlying basis of this noncanonical TIP60 function in suppressing transcription remains elusive.

Here, we uncover the mechanism by which endogenous RAP1 maintains native gene expression. We show that RAP1 transcriptional function in mammalian cells is independent of its telomere association and does not involve binding to DNA. Instead, our data reveal that non-telomeric RAP1 interacts with the TIP60/p400 complex by binding cooperatively to TIP60 and Epc1 and enhances TIP60 acetylation activity. Notably, loss of RAP1 in mESCs triggers a $2 \mathrm{C}$-like state and modulates the repressive activity of TIP60/p400 on a subset of 2 C-stage genes, especially ones proximal to the endogenous retroviral MERVL elements. In summary, our data uncover an unprecedented link between a conserved telomere binding protein and the TIP60/p400 complex in the regulation of totipotency.

\section{Results}

\section{Endogenous Rap1 maintains native transcription independent of telomeres}

It has been proposed that the function of mammalian RAP1 in gene regulation is similar to budding yeast Rap1 and driven by its association with promoter elements. Consistent with this hypothesis, a study hinted at direct binding of mammalian RAP1 to DNA in a sequence non-specific manner (Arat and Griffith 2012), and ChIP-seq analysis highlighted several genomic loci that are bound by Rap1 (Martinez et al. 2010; Yang et al. 2011). To gain better insight into the mechanism by which Rap1 regulates transcription, we employed CRISPR/Cas9 to generate mice carrying Rap $1^{1312 R}$ (Figure 1A), an allele that is incapable of binding TRF2 (Chen et al. 2011). Fertilized oocytes were 
injected with mRNA encoding Cas9 nuclease, a single-guide RNA (sgRNA) targeting exon 3, and a single-stranded DNA oligo donor (ssODN) coding for Rap $1^{1312 R}$. Zygotes were implanted into surrogate female mice, and proper targeting was confirmed by genotyping PCR and Sanger sequencing (Figure 1B-C).

To confirm the release of RAP1 from telomeres in Rap1/312R//312R (also labeled Rap $1^{I R / I R}$ ) mouse embryonic fibroblasts (MEFs), we performed indirect immunofluorescence coupled with fluorescence in situ hybridization (IF-FISH). Consistent with previous reports (Chen et al. 2011; Yeung et al. 2013), Rap1 exhibited a diffuse nucleoplasmic staining pattern in Rap $1^{1312 R / 1312 R}$ MEFs and contrasted with the punctate staining that co-localized with telomeres in Rap $1^{+/+}$cells (Figure 1D). We then fractionated lysates into cytosolic, nucleoplasmic, and chromatin-bound fractions and showed that whereas wild type RAP1 was strongly bound to chromatin, Rap $1^{1312 R}$ lost its chromatin association and as distributed between the nucleoplasm and cytoplasm (Figure 1E). Furthermore, Western blot analysis revealed that RAP1 protein abundance was reduced 5-fold in Rap1 ${ }^{1312 R / 1312 R}$ MEFs relative to wild type cells (Figure 1F). Similarly, overall Rap1 levels were reduced when examined in different tissues harvested from Rap $1^{1312 R / 1312 R}$ mice (Figure S1A-B). This observation is in accordance with previous reports indicating that binding to TRF2 stabilizes RAP1 protein levels (Celli and de Lange 2005; Sfeir et al. 2010). Along these lines, treatment with the proteasome inhibitor, MG132 (5 $\mu \mathrm{M}$ for 11 hours) increased RAP1 abundance by two- and six-fold in Rap $1^{+/+}$ and Rap1/312R//312R MEFs, respectively (Figure S1C-D). In addition, coimmunoprecipitation (CoIP) experiments in HEK293T cells showed that Rap1 immunoprecipitated with K48Ub, providing further evidence for its K48-linked 
ubiquitinylation (Figure S1E). Altogether, our results show that at telomeres, mammalian Rap1 is stabilized by its interaction with TRF2, while the extratelomeric RAP1 pool is tightly regulated by proteasomal degradation.

We then performed RNA sequencing (RNA-Seq) on $R a p 1^{-/}$, Rap1 $1^{+/+}$and Rap $1^{1312 R / 1312 R}$ primary MEFs. Principal component analysis (PCA) of transcriptomes showed close clustering of the $R a p 1^{+/+}$and $R a p 1^{1312 R / / 312 R}$ samples apart from $R a p 1^{-/-}$ samples (Figure S1F). Differential gene expression analysis using DESeq2 identified 654 differentially expressed genes in $\operatorname{Rap}^{-/-}$vs. Rap $1^{+/+}$MEFs $(\mathrm{FC}>1.5$, FDR < 0.1 ; Supplementary Table S1). These genes were involved in various pathways related to cellcell signaling and developmental processes (Figure S1G; Supplementary Table S2). Interestingly, gene expression (653 of $654,99.8 \%$ ) was largely maintained in Rap1/312R/1312R MEFs relative to wild type cells (Figure 1G). Taken together, our data suggest that despite the overall reduction in Rap1 levels in $R a p 1^{1312 R / / 312 R}$ cells, a small pool of extra-telomeric RAP1 is sufficient to fully maintain gene expression control. Furthermore, we establish that the function of mammalian RAP1 in gene expression is completely independent of TRF2 binding and telomere localization.

\section{Rap $1^{1312 R}$ does not directly associate with chromatin}

In budding yeast, extra-telomeric RAP1 binds directly to interstitial genomic sites including several gene promoters (Bram and Kornberg 1985; Huet et al. 1985; Shore and Nasmyth 1987; Vignais et al. 1987; Chambers et al. 1989; Platt et al. 2013; Song et al. 2020). Similarly, in human and mouse cells, wild type Rap1 was detected at many sites throughout the genome (Martinez et al. 2010; Yang et al. 2011; Martinez et al. 2016) with 
a notable overlap with TRF2 binding sites. Given that Rap1 $1^{1312 R}$ fully maintains transcriptional regulation, we sought to employ this separation-of-function allele to identify TRF2-independent RAP1 binding sites and, thus, more relevant to its role in gene expression. We transduced SV40LT-immortalized Rap1\%- MEFs with HA-Rap1 and HARap1-I312R and noted that both alleles accumulated at similar levels when exogenously expressed (Figure S2A). As predicted, HA-Rap1 localized to telomeres whereas HA-RapI312R was largely nucleoplasmic (Figure S2B). Chromatin immunoprecipitation (ChIP) using anti-HA antibody followed by dot blot analysis showed significant association of telomeric DNA with HA-RAP1 but not with HA-RAP1-I312R (Figure 2A). In addition, analysis by high-throughput sequencing revealed a 100-fold enrichment for reads containing telomere repeats in cells expressing wild type Rap1 (Figure 2B). We performed peak calling using MACS2 ( $q<0.05)$ and identified 109 wild type Rap1 binding sites: 39 subtelomere sites and 70 other loci scattered throughout the genome (Figure 2C, representative peaks Figure S2C-D; Supplementary Table S3). This analysis is consistent with previous observations that RAP1 localizes to discrete sites throughout the genome (Martinez et al. 2010; Yang et al. 2011; Martinez et al. 2016). Notably, using broad as well as narrow peak calling algorithms, we did not identify any genomic binding sites for RAP1 $1^{1312 R}$ (Figure 2C). Specifically, RAP1 $1^{1312 R}$ showed no binding near telomeres (Figure 2D) nor at interstitial peaks bound by wild type Rap1 (Figure 2E).

Having failed to detect RAP1 $1^{1312 R}$ binding to DNA by ChIP, we then turned to in vitro assays to directly assess the binding of Rap1 to DNA. We performed electrophoretic mobility shift assays (EMSAs) using purified protein and initially found that His-tagged RAP1 binds to DNA with no sequence specificity and is also capable of associating with 
purified nucleosomes (Figure 2F, S2E-F). Importantly, upon removal of the His-tag used for purification purposes, the binding of RAP1 to free and nucleosome-bound DNA was abrogated (Figure 2G; Figure S2G-H). The confounding impact of histidine tags on DNAbinding activity of purified proteins has been reported in the literature (Paul et al. 2020) and could well explain earlier studies that showed nonspecific binding of human RAP1 to DNA in vitro (Arat and Griffith 2012). Taken together, our data confirm that unlike budding yeast Rap1, the mammalian counterpart is incapable of binding DNA directly, and therefore, the mechanism by which RAP1 regulates gene expression in higher eukaryotes must have diverged from budding yeast.

\section{Proximity-based biotinylation reveals extratelomeric Rap1 interactors}

We next used proximity-based biotinylation to identify RAP1 protein interactions and provide insight to the potential mechanisms by which extratelomeric Rap1 regulates gene expression (Roux et al. 2012). To that end, we transduced SV40LT-immortalized Rap1\%-MEFs with BiolD-tagged RAP1 and RAP1-I312R and established independent clonally derived cells that expressed similar levels of the RAP1 variants. We reasoned that exploring the RAP1 proteome in the context of RAP1-I312R will enable the identification of extra-telomeric RAP1 interactors relevant to its function in gene regulation. As expected, BioID-RAP1 colocalized with telomere TTAGGG (Figure 3A) and interacted with TRF2 (Figure 3B), whereas BiolD-RAP1-I312R expressed diffusely throughout the nucleus (Figure S3A) and failed to associate with TRF2 (Figure 3B).

We then performed mass spectrometry analysis following streptavidin pull-down of nuclear extracts (silver stain and streptavidin-HRP, Figure S3B; Supplementary Table 
S4) and detected 189 and 227 interactors of RAP1 and RAP1-I312R, respectively, that were enriched at least 2-fold (peptide-spectrum match for protein abundance) over the empty vector (BiolD) control (Supplementary Table S5). As expected, proteins exclusively associating with wild type RAP1 included shelterin subunits TRF2, TPP1, and TIN2, (Figure 3C; Figure S3D). Notably, among factors enriched in the context of Rap1-I312R, we identified six members of the TIP60/p400 histone acetyltransferase complex, EPC1 and its paralog EPC2, DMAP1, p400, TRRAP, and BRD8 (Figure 3C; Figure S3C). Furthermore, statistical overrepresentation test of biological processes using PANTHER Classification System revealed statistical significance for Histone H2A Acetylation, Histone H4 Acetylation, and DNA Repair in RAP1-I312R (Figure 3D; Supplementary Table S6).

To validate the mass spectrometry data, we performed ColP of Flag- and HAtagged proteins co-expressed in HEK293T and demonstrated stable interaction between RAP1 and TIP60, EPC1, EPC2, and DMAP1 (Figure 3E-G). Importantly, the interaction between RAP1 and EPC1 was not diminished upon treatment with DNase (Figure S3D), and was evident when using purified recombinant proteins (GST-EPC1 and His-RAP1) (Figure S3E), suggesting that the two proteins interact independent of DNA binding. In conclusion, our results reveal that extra-telomeric RAP1 is a binding partner of the TIP60/p400 complex.

Rap1 associates with Epc1 and Tip60, enhancing histone acetyltransferase (HAT) activity 
The TIP60/p400 histone acetyltransferase is a multimeric complex composed of $>18$ subunits (Doyon and Cote 2004). TRRAP and p400 serve as scaffolds for the assembly of the complex whereas TIP60, a lysine acetyltransferase (KAT), is the catalytic subunit responsible for acetylation of histones $\mathrm{H} 2 \mathrm{~A}, \mathrm{H} 4, \mathrm{H} 2 \mathrm{~A} . \mathrm{Z}$ and other nonhistone proteins, including Tp53 (Steunou et al. 2014). Epc1 comprises four conserved domains (Figure 4A). The N-terminal EPcA domain assembles the core 4-subunit catalytic module that includes Tip60 (a.k.a. piccolo NuA4 or picNuA4), while the central EPcB domain binds p400 to effectively bridge the rest of the TIP60/p400 complex (Boudreault et al. 2003; Doyon et al. 2004; Selleck et al. 2005; Auger et al. 2008; Chittuluru et al. 2011; Xu et al. 2016; Setiaputra et al. 2018). Using deletion mutants of the Epc1 subunit, we found that the EPcA domain is necessary and sufficient to interact with Rap1 (Figure 4A-C), placing the telomere binding protein at the Epc1/TIP60 interaction interface. Through a reciprocal approach, we identified the C-terminal RCT domain of Rap1 to be necessary for binding to EPC1 (Figure 4D). The RAP1 RCT domain also binds TRF2, suggesting that binding of RAP1 to TIP60/p400 and TRF2 is mutually exclusive. Consistent with this notion, we found no evidence for TRF2 binding to EPC1/RAP1, in contrast TRF2 reduces the EPC1-RAP1 interaction (Figure S4A). Taken together, these data implicate RAP1 in two separate complexes, being part of shelterin at telomeres and associating with TIP60/p400 during transcriptional regulation.

We then explored whether RAP1, EPC1, and TIP60 form a trimeric complex. To that end, we co-expressed all three proteins in HEK293T cells and performed ColP experiments. Using Rap1 as a bait, we found that Rap1-Epc1 and Rap1-Tip60 interactions were strongly enhanced in the presence of Tip60 and Epc1, respectively 
(Figure S4B). As expected, the effect was dependent on the EPcA domain of EPC1

(Figure S4C). In a parallel approach, we used EPC1 as bait and found that TIP60 greatly enhanced Rap1/Epc1 association (Figure 4E). Notably, histone acetyltransferase (HAT) assays revealed that Rap1 binds EPC1/TIP60 in an active conformation (Figure S4D) and increases Epc1/Tip60 HAT activity (Figure 4F-G). This was confirmed by ColP of EPC1/TIP60/RAP1 from HEK293T cells (Figure 4F) and by in vitro addition of affinity purified human RAP1 protein to purified native TIP60/p400 complexes (Figure 4G). Altogether, we conclude that extratelomeric Rap1 associates with the TIP60/p400 complex and cooperatively binds to and modulates the HAT activity of Tip60/KAT5, thus illuminating the potential for Rap1 to act as a cofactor to regulate gene expression through histone modifications.

\section{Rap1 suppresses the 2-cell-like state in mouse embryonic stem cells}

It has been established that the TIP60/p400 complex is essential for stem cell selfrenewal and survival (Fazzio et al. 2008; Acharya et al. 2017), and members of the TIP60 complex (e.g. TIP60, DMAP1 and Ep400) suppress the emergence of "2-cell-like" (2Clike) cells in mouse embryonic stem cell cultures (mESC) (Rodriguez-Terrones et al. 2018). 2C-like cells were identified based on their resemblance to embryos at the twocell stage of development (Macfarlan et al. 2012) and represent a unique window during preimplantation development when the zygotic genome becomes activated, marking a brief period of totipotency. During zygotic genome activation (ZGA), murine endogenous retrovirus with leucine tRNA primer (MERVL) elements are derepressed, along with the upregulation of several 2C genes such as Zscan4 and Dux. Inner cell mass (ICM) derived 
mESC cultures contain a small fraction $(<1 \%)$ of 2 C-like cells exhibiting a $2 \mathrm{C}$ transcriptional state, providing a useful model to study totipotency (Macfarlan et al. 2012; Fu et al. 2019; Fu et al. 2020). Emergence of the 2C-like state is regulated by an atypical chromatin-assembly pathway involving FACT and CAF-1 histone chaperone complexes, the noncanonical PRC1 complex, and TIP60/p400 (Ishiuchi et al. 2015; RodriguezTerrones et al. 2018; Chen et al. 2020), although the exact molecular mechanisms are still to be determined.

The direct binding of RAP1 to members of the TIP60 complex (Figure 3D) prompted us to investigate whether RAP1 regulates the $2 \mathrm{C}$-like state. To that end, we established independent mESC cultures from $R a p 1^{+/+}$and $R a p 1^{-/-}$mouse preimplantation blastocysts and performed RNA-seq. Transcriptomic analysis identified 202 upregulated genes (Figure 5A, Figure S5A; Supplemental Table S7), half of which $(102 ; 50.5 \%)$ were previously categorized as genes expressed in 2C-like cells (Fu et al. 2020) (Figure 5AB), including the Zscan4 locus that we corroborated using RT-qPCR and IF (Figure S5BC). We also observed that Rap1/- mESCs displayed increased expression of the MERVL retrotransposon elements MT2_Mm, MERVL-int, and MERVL_2A-int, known to be derepressed in 2C-stage embryos (Figure 5C and 5SD; Supplementary Table S8). Lastly, to address whether RAP1 suppresses the 2C-like state independent of telomere binding, we derived mESC cultures from Rap1/312R//312R mouse blastocysts (Figure S5E) and found a similar expression of $2 \mathrm{C}$-like genes in Rap $1^{1312 R / / 312 R} \mathrm{mESC}$ s relative to wild type (Figure S5F-G). In summary, our results uncover an unexpected function for a highly conserved telomere binding protein in the regulation of pluripotency. 
The interplay between RAP1 and the TIP60/p400 complex on mESC gene expression

Having established that extratelomeric RAP1 suppresses the $2 \mathrm{C}$-like state in mESCs, we sought to better understand the interplay between Rap1 and Tip60/p400 during repression of 2C genes. We depleted Tip60, Epc1, Dmap1, and Ep400 individually by siRNA in $\mathrm{Rap}^{+/+}$and Rap1/- mESCs (Figure S6A), and RNA-seq analysis was performed. We first focused on the TIP60/p400 complex and interrogated the effect of depleting individual subunits on the expression of 2C-stage genes (Fu et al. 2020). Kmeans clustering highlighted 5 distinct 2C-state gene clusters (Figure 5D). Depletion of Tip60/p400 subunits showed the expected reduction in transcription at three gene clusters (Figure 5D, clusters \#3, \#4, and \#5). As for clusters \#1 and \#2, depletion of Tip60, Ep400, and Dmap1 led to a paradoxical increase in 2C gene expression (Figure 5D, Clusters \#1 and \#2), suggestive of a repressive function for this complex in mESCs transcription (Fazzio et al. 2008; Rodriguez-Terrones et al. 2018). Of note, the various 2C gene clusters were not equally sensitive to inhibition of the various TIP60 members. For example, depletion of Dmap1 and Tip60 lead to opposite effects on gene expression within cluster \#5. Furthermore, Tip60 loss majorly impacted gene cluster \#4, whereas p400 and Dmap1 depletion caused significant downregulation in gene expression for cluster \#3. The latter observation can be explained by Dmap1/p400-mediated deposition of the histone variant H2A.Z as opposed to TIP60-driven histone acetylation. Overall, this sort of analysis revealed a high degree of complexity in how the TIP60/p400 complex regulates $2 \mathrm{C}$-stage genes in mESCs, with certain subunits acting as negative repressors while others exerting a positive effect on gene transcription. 
We next overlayed the impact of Rap1 depletion on Tip60/p400 dysregulation of 2C gene expression and noted that half of all 2C genes (53.5\%; 571 of 1068) were sensitive to Rap1 loss (Figure 5D). Strikingly, RAP1-sensitive genes were further upregulated upon Tip60/p400 inhibition, including Zscan4c and MERVL (Figure S6B-C). Instead, gene clusters that were downregulated upon Tip60/p400 knockdown were largely insensitive to RAP1 (cluster \#3, \#4, and \#5). Taken together, these results implicate RAP1 in the noncanonical and poorly understood function of TIP60/p400 during 2C genes supression.

\section{Increased histone acetylation at MERVL upon Rap1 loss}

Examination of the Zscan4 locus and the MERVL LTR MT2_Mm by ChIP-seq revealed increased $\mathrm{H} 4 \mathrm{Ac}$ and $\mathrm{AcH} 2 \mathrm{~A} . \mathrm{Z}$ abundance in $\mathrm{Rap1}^{-/}$cells, that was further enhanced upon depletion of Dmap1 (Figure 5E-G). As a control, we show that Rap1 insensitive genes did not exhibit differences in H4Ac or AcH2A.Z levels between Rap1+/+ and Rap $^{\text {- }}$ mESCs. Furthermore, genes that were downregulated upon Dmap1 depletion showed the expected decrease in $\mathrm{H} 4 \mathrm{Ac}$ and $\mathrm{AcH} 2 \mathrm{~A} . \mathrm{Z}$ at promoter regions (Figure $5 \mathrm{H}$ ). Strikingly, a significant fraction of genes proximal to MERVL MT2_Mm elements were upregulated in Rap $^{-/}$mESCs (Figure $5 \mathrm{I}-\mathrm{J}$ ), suggesting that a significant proportion of genes differentially expressed upon Rap1 loss were at fixed distances from this class of repeat elements. We found no proximal distance association between upregulated genes and unrelated retroviral elements such as LINE1 (Lx5, Lx3_Mus, L1Md_A, L1Md_F) (Figure 5I). This implies that upregulation of a subset of 2C genes in the absence of Rap1 can be ascribed to the induction of genes proximal to MERVL. It has been reported that 
in 2C-like cells MERVL elements can serve as enhancers and create sites of cryptic transcription initiation, influencing proximal genes (Macfarlan et al. 2012). Accordingly, the paradoxical de-repression of $2 \mathrm{C}$ genes upon Tip60/p400 and Rap1 depletion could be the result of cis-effects of increased MERVL repeat elements expression. 


\section{Discussion}

Our study sheds light on the mechanism by which Rap1 regulates gene expression in mammals by establishing that RAP1 maintain native transcription independent of its association with telomeres. We find that extratelomeric RAP1 responsible for its transcriptional function does not bind to discrete genomic DNA loci. Instead, this conserved telomere binding protein modulates the HAT activity of the Tip60/p400 complex. Furthermore, we uncover an unanticipated role for mammalian RAP1 in regulating the repressive activity of the TIP60/p400 complex on 2C-stage genes and endogenous retroviruses in mESCs.

\section{Transcriptional regulation: an ancestral function for the most conserved telomere binding protein}

RAP1 is the most highly conserved telomere binding protein and in unicellular eukaryotes serves an essential function in telomere maintenance by regulating telomere length, preventing telomere fusions, and suppressing telomere-telomere recombination events (Kanoh and Ishikawa 2001; Pardo and Marcand 2005; Nanavaty et al. 2017). When compared to its chimpanzee counterpart, the gene encoding human RAP1 shows little divergence (0.25 aa changes/100 aa) relative to other shelterin subunits (0.65 aa changes/100 aa for TRF2, TRF1, and TIN2, respectively) (Kabir et al. 2014). Yet, RAP1 is largely dispensable for telomere function and cell viability in mammals (Sfeir et al. 2010; Kabir et al. 2014). This paradox raises a question related to the selective pressure for RAP1 conservation in higher eykaryotes. We speculate that the function of RAP1 in gene regulation might underly such conservation. In budding yeast, Rap1 binds to DNA 
sequences at gene promoters and is necessary to maintain high expression of genes encoding ribosomal proteins and glycolytic enzymes, without which cell growth and proliferation are greatly stunted (Bram and Kornberg 1985; Huet et al. 1985; Shore and Nasmyth 1987; Vignais et al. 1987; Chambers et al. 1989). Additionally, in both yeast and T. brucei, Rap1 maintains repression of telomere/subtelomere regions, preventing aberrant expression of genes proximal to chromosome ends, such as the variant surface glycoprotein (VSG) genes found in T. brucei subtelomeres (Yang et al. 2009). Rap1 transcriptional activity in budding yeast is also linked to telomeres. Specifically, its binding to telomeres represses the transcription of telomeric repeat-containing RNA (TERRA) a long non-coding RNA in subtelomere regions - by recruiting of Rif1/2 and Sir2/3/4 complexes (Iglesias et al. 2011). Furthermore, as telomeres shorten in budding yeast, the abundance of extratelomeric RAP1 increases, facilitating its localization to additional target genes (called NRTS, for new Rap1 targets at senescence) to regulate transcription (Platt et al. 2013; Song et al. 2020). In contrast, our study shows that mammalian RAP1 transcriptional activity is uncoupled from telomere binding, with independent pools of RAP1 associating with either TRF2 or TIP60. We show that mutant RAP1 (Rap1 $1^{1312 R}$ ) that cannot bind TRF2 or localize to telomeres fully complements gene expression (Figure 1G). Furthermore, whereas yeast Rap1 binds directly to DNA sequences at gene promoters to regulate transcription, we found that the extratelomeric pool of mammalian RAP1 does not bind genomic loci (Figure 2D-E) and mammalian Rap1 lacks DNA binding activity (Figure 2G, S2G-H). Thus, although Rap1 function in transcription regulation is conserved in higher eukaryotes, the mechanism by which Rap1 regulates transcription has diverged. 


\section{RAP1 as a regulator of the TIP60 complex}

We establish that extratelomeric RAP1 associated with TIP60/p400, a histone acetyltransferase complex with a fundamental role in the regulation of gene transcription, as demonstrated by proximity labeling as well as co-immunoprecipitation with the Tip60, Epc1/Epc2, and Dmap1 subunits of the complex (Figure 3E). RAP1 binds to the Epc1 Nterminal EPCA domain through its C-terminal RCT domain (Figure 4). TRF2 also binds Rap1-RCT and appears to compete with EPC1 (Figure S4A), suggesting that RAP1 binding to TIP60/p400 is mutually exclusive with TRF2. This is consistent with the observation that Rap1 maintains native transcription independent of TRF2 and provides evidence that RAP1 associates with multiple regulatory protein complexes through its RCT domain. This is similar to budding yeast, where Rap1 utilizes its RCT domain to recruit a diverse set of regulatory factors depending on the genomic and functional context, for example, Rif1/Rif2 at telomeres to regulate telomere length (Hardy et al. 1992b; Wotton and Shore 1997) and Sir3/Sir4 at HML/HMR to maintain transcriptional silencing (Moretti et al. 1994; Moretti and Shore 2001). Association of RAP1 with the TIP60/p400 complex is conserved between humans and mice, as demonstrated by a recent publication that used a similar proximity-dependent biotinylation approach in human cells (Go et al. 2021). In addition, our study shows RAP1 modulates TIP60/p400 HAT activity (Figure 4F-G), establishing RAP1 as a transcriptional cofactor within a chromatin modifying complex. Future structural and biochemical studies are necessary to understand how Rap1 regulates the activity of the Tip60/p400 complex. 
Importantly, we found that loss of RAP1 synergizes with Tip60/p400 depletion to increase $\mathrm{H} 4$ and H2A.Z acetylation at promoters of upregulated 2C genes (Figure 5E-F). The noncanonical activity of TIP60/p400 on mESC gene expression has been previously noted (Fazzio et al. 2008; Chen et al. 2013) and contrasts the case in somatic cells, where TIP60/p400 is primarily a transcriptional activator that leads to histone acetylation. So far, the underlying molecular mechanism of TIP60 mediated repression of gene expression remains completely unknown, and our data implicated RAP1 in the non canonical function of TIP60. Furthermore, our results suggest that the majority of RAP1 dysregulated genes are proximal to MERVL repeat elements which also exhibit elevated $\mathrm{H} 4 / \mathrm{H} 2 \mathrm{~A} . \mathrm{Z}$ acetylation (Figure 5G-I).This proximity-dependent effect on gene expression has also been observed upon depletion of the FACT and CAF-1 histone chaperone complexes, contexts in which cryptic transcription generates MERVL-fused chimeric transcripts (Ishiuchi et al. 2015; Chen et al. 2020). Taken together, we propose a model whereby the activation of endogenous retroviral elements MERVL induces the transcription of proximal genes in context of Rap1 deficiency. However, we cannot exclude that the effect of Rap1 on 2C genes is downstream of Zscan4 activation (Zhang et al. 2019) or perhaps due to differential acetylation of non-histone proteins which is another known mechanism by which Tip60/p400 modulates gene expression (Sapountzi and Cote 2011).

\section{Telomere binding proteins and totipotency}

An unlikely link between telomeres, telomere binding proteins, and pluripotency emerged in recent literature. Loss of TRF1 in stem cells leads to increased TERRA levels that in turn modulated the recruitment of the PRC2 repressive complex to alter 
pluripotency genes expression (Marion et al. 2019). More recently, depletion of TRF2 in mESCs was shown to induce the expression of 2C-stage genes, including Zscan4 which contributed to telomere protection in the absence of TRF2 (Markiewicz-Potoczny et al. 2021). The latter study highlights an unexpected link between totipotency and telomere protection mechanisms. Our study unravels yet another connection between telomere biology and totipotency, as we find that RAP1 suppresses a $2 \mathrm{C}$-like state in mESCs by enhancing the repressive activity of TIP60/p400 on MERVL and other 2C genes (Figure 5A-D). In effect, our study highlights how the telomere binding protein Rap1 interfaces with chromatin modifying complexes in the control of totipotency. It is tempting to speculate that the regulation of transcription at retroviral repeat elements constitute an ancestral function for RAP1, and possibly other shelterin subunits prior to being co-opted as a telomere binding proteins. Finally, further studies are necessary to explore the impact of this telomere binding protein on other classes of endogenous retrovirus and in different biological settings.

\section{Acknowledgements:}

We thank members of the Sfeir lab for feedback and comments on the manuscript. pRK5HA-Ubiquitin-K48 was a gift from Ted Dawson (Addgene, \#17605). We are thankful to Karim-Jean Armache for guidance on RAP1 gel shift assays. Catherine Lachance is acknowledged for purified NuA4/TIP60 and chromatin fractions. We acknowledge Beatrix M. Ueberheide and the Proteomics lab as well as Sang Y. Kim and the Rodent Genetic Engineering lab at NYU School of Medicine. We thank the Genome Technology Center at NYU School of Medicine and the Integrated Genomics Operation at Sloan Kettering 
Institute, MSKCC. This work was supported by a grant from the NIH (R01 DK102562) to A.S. and CIHR (FDN-143314) to J.C. R.M.B. is supported by a training grant from NIH (1F30 DK118901). C.H. lab is funded by internal institutional support of the Institute of Biophysics of the Czech Academy of Sciences (68081707), the Czech Science Foundation, project 19-18226S, and Ministry of Education, Youth and Sports of the Czech Republic. project LTAUSA19024

\section{Authors Contribution:}

A.S., R.M.B. conceived the experimental design. R.M.B. performed experiments with the help of P.S., O.S., and W.K. M.A. in C.H. lab performed EMSA and RAP1 purification. A.M. in J.C. lab performed HAT assays. P.D. prepared nucleosomes for EMSA. A.S. and R.M.B. wrote the manuscript. All authors discussed the results and commented on the manuscript.

\section{Author information:}

Agnel Sfeir is a co-founder, consultant, and shareholder in Repare Therapeutics. Correspondence and requests for materials should be addressed to A.S. (sfeira@mskcc.org).

Figure Legends:

Figure 1. Rap1 maintains gene transcription independent of telomeres. A) Schematic representation of CRISPR/Cas9 gene editing strategy to substitute Rap1 
isoleucine 312 to arginine. Successful targeting creates an Acil restriction site to be used during genotyping. Single-stranded oligo donor (ssODN, black line) single-guide RNA (sgRNA) cut site (red scissors) are indicated. B) PCR genotyping of tail-tip DNA from two Rap $1^{1312 R /+}$ heterozygous mice following gene targeting. C) Example Sanger sequencing of Rap $1^{1312 R /+}$ heterozygous mouse. D) Representative image of IF-FISH in $R a p 1^{+/+}$, Rap 1/-, and Rap1 1312R//312R (labelled as Rap1/R/IR) MEFs for Rap1 (green) and telomeres (red) using Rap1 antibody and TTAGGG PNA probe, respectively. DAPI (blue) is used as

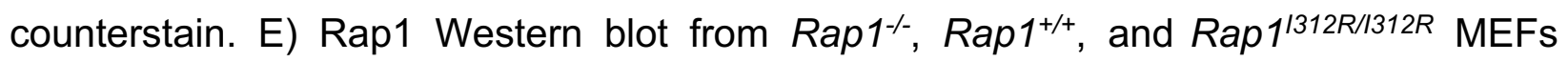
following subcellular fractionation into cytoplasmic (Cyt), nucleoplasmic (Nuc), and chromatin-bound (CBF) fractions. $\alpha$-tubulin and histone $\mathrm{H} 3$ are loading controls for Cyt and $\mathrm{CBF}$, respectively. Blot is representative of $n=2$ biological replicates. F) Immunoblot for Rap1 from whole cell lysates obtained from $\operatorname{Rap}^{-/-}(\mathrm{n}=2), \operatorname{Rap}^{+/+}(\mathrm{n}=3)$, and $\operatorname{Rap}^{1312 R / 1312 R}(\mathrm{n}=3)$ MEFs. Rap1 relative abundance was determined by normalizing to $\gamma$-tubulin. G) Hierarchically clustered heatmap representing RNA-seq data for differentially expressed genes (DEGs) between Rap $1^{+/+}$and Rap1\% MEFs (FC > 1.5; FDR $<0.1 ; \mathrm{n}=$ 3 biological replicates per genotype).

Figure 2. Rap1-I312R does not bind to genomic loci or DNA. A) Dot blot for telomere repeats following ChIP using anti-HA antibody in cells expressing HA-tagged Rap1-WT, Rap1-I312R, or empty vector (EV) control ( $n=2$ biological replicates). Signal intensity is determined by normalizing to input. B) High-throughput sequencing of ChIP samples as in $A$. Telomere binding was determined by calculating the proportion of reads with at least three telomere $(\mathrm{TTAGGG})_{3} /(\mathrm{CCCTAA})_{3}$ repeats. Data are the mean \pm standard deviation 
of $n=4$ biological replicates. C) Summary of ChIP-seq peak calling analysis which identified 109 peaks in HA-Rap1-WT samples (MACS2; q <0.05). Peaks were classified as subtelomeric if localized within $500 \mathrm{~kb}$ from the telomere. D) Heatmap representing ChIP-seq profiles of HA-Rap1-WT peaks at chromosome ends. E) Heatmap representing ChIP-seq profiles of HA-Rap1-WT interstitial peaks. F) Electrophoretic mobility shift assay (EMSA) using His-tagged Rap1 (0 to $15 \mu \mathrm{M}$ ) and a 74bp TTAGGG/AATCCC doublestranded DNA (100 nM). G) EMSA using non-His-tagged-Rap1 (0 to $15 \mu \mathrm{M})$ and a 74bp

TTAGGG/AATCCC double-stranded DNA (100 nM).

Figure 3. Proximity-dependent biotinylation reveals extratelomeric Rap1 binding partners. A) Representative image of IF-FISH using streptavidin antibody in Rap $1^{-1-}$ MEFs expressing BiolD-Rap1-WT stained for BiolD-Rap1 (magenta), biotin (green), and telomeres (red) using anti-Flag antibody, streptavidin, and TTAGGG PNA probe, respectively. DAPI (blue) is used as counterstain. B) Immunoblot for Rap1 and TRF2 following streptavidin pull-down in Rap1- MEFs expressing BiolD-Rap1-WT ( $\mathrm{n}=3$ biological replicates; clones C1, C2, C3), BiolD-Rap1-I312R ( $n=4$ biological replicates; clones C1, C2, C3, C4), and BiolD alone (EV). Where indicated, cells were treated with biotin $(50 \mu \mathrm{M})$ for 20 hours prior to harvest. C). Scatter plot representing $\log _{2}$ fold change in peptide-spectrum match (PSM) of proteins identified by BiolD-Rap1-WT versus BiolDRap1-I312R. Fold change values were calculated relative to no biotin and BiolD alone controls. Each dot represents a unique protein. Known Tip60/p400 (green, purple) and shelterin (red) complex members are indicated. D) Graphical representation of top 10 
biological processes overrepresented in BiolD-Rap1-I312R streptavidin pull-down (FC > 2) using PANTHER Classification System statistical overrepresentation test. E) ColP of Myc-tagged Tip60/p400 subunits (Tip60, Epc1, Epc2, Dmap1, Brd8, Ruvbl1, Actl6a) and HA-Rap1 following co-transfection in HEK293T cells. F) Reciprocal CoIP of HA-Rap1I312R and Myc-tagged Epc1 or Epc2. ColP of HA-Rap1 or HA-Rap1-I312R with TRF2 is used as a control. G) Reciprocal ColP of HA-Rap1 and Myc-Tip60.

Figure 4. Rap1 forms a complex with and modulates the histone acetyltransferase (HAT) activity of Tip60/Epc1. A) Schematic illustration of Epc1 and Rap1 protein domains and deletion mutant constructs used for ColP assays. B) ColP of Flag-Epc1 deletion mutants and Myc-Rap1 in co-transfected HEK293T cells. Western blot analysis for Input and IP sample was performed with the indicated antibody. C) ColP of Flag-Epc1 EPcA domain and Myc-Rap1. D) ColP of Flag-Rap1 deletion mutants and Myc-Epc1. E) ColP of Flag-Epc1, Myc-Tip60, and HA-Rap1. F) Histone acetyltransferase (HAT) activity assays performed using ColPs from $E$ on core histones. Data are the counts per minute (CPM) mean \pm standard deviation of $n=2$ technical replicates; two-way ANOVA, Tukey's multiple comparison test; * $p$-value $<0.0001$. G) HAT activity assay using affinity purified EPC1/TIP60 and Rap1 (increasing amounts) on short oligonucleosome chromatin. Bovine serum albumin (BSA) is a negative control. Data are CPM mean \pm standard deviation of $n=3$ technical replicates; two-way ANOVA, Tukey's multiple comparison test; * $p$-value $<0.01$ 


\section{Figure 5. Rap1 suppresses the $2 \mathrm{C}$-like state by enhancing Tip60/p400 repression}

of $2 \mathrm{C}$ genes. A) MA plot of $\log _{2}$ fold changes in gene expression in $R a p^{-/-} v s$. Rap $1^{+/+}$ mESCs. Upregulated (light red) and downregulated (light blue) genes are indicated (FC $>1.5 ; \mathrm{FDR}<0.1 ; \mathrm{n}=5$ biological replicates). $2 \mathrm{C}$-stage genes are highlighted in dark red. B) Hierarchically clustered heatmap representing RNA-seq data of $2 \mathrm{C}$ genes upregulated in $R a p^{-/} v s . R a p 1^{+/+}$mESCs ( $n=5$ biological replicates). C) Volcano plot of differential repeat expression analysis in $R a p 1^{-/}$vs. Rap $1^{+/+}$mESCs. Upregulated (red) and downregulated (blue) repeats are indicated (FC $>2$; FDR $<0.1 ; n=5$ biological replicates). D) Kmeans ( $k=5$ ) clustered heatmap representing RNA-seq data of $2 \mathrm{C}$ genes in $R a p 1^{+/+}$(grey bar) and Rap1/- (red bar) mESCs treated with siRNAs targeting Tip60/p400 subunits (Epc1, Tip60, p400, Dmap1) or nontargeting (siNT) control. 3 biological replicates were used per condition. E) ChIP-seq of H4Ac and AcH2A.Z profiles at the Zscan4d gene locus in Rap ${ }^{+/+}$(grey bar) and Rap $1^{-/}$(red bar) mESCs transfected with siRNA targeting Dmap1 or nontargeting (siNT) control. Profiles plotted are representative of $n=3$ biological replicates. F) Density plot centered at all MT2_Mm sites for H4Ac and AcH2A.Z ChIP-seq data. Density plots are representative of $n=3$ biological replicates. G) ChIP-seq profiles of $\mathrm{H} 4 \mathrm{Ac}$ and $\mathrm{AcH} 2 \mathrm{~A} . \mathrm{Z}$ at a representative MERVL site in $R a p 1^{+/+}$(grey bar) and Rap1\% (red bar) mESCs transfected with siRNA targeting Dmap1 and non-targeting control (siNT). H) ChIP-seq profiles of H4Ac and AcH2A.Z at a representative downregulated gene (Btg2) locus in Rap1//+ (grey bar) and Rap1// (red bar) mESCs transfected with siRNA targeting Dmap1 or nontargeting (siNT) control. I) Plot of the proportion of differentially expressed genes (DEGs) in $R a p 1^{+/+} v s$. Rap $1^{-/-}$ mESCs $(F C>1.5 ; F D R<0.1)$ at fixed distances from the indicated MERVL $\left(M T 2 \_M m\right.$, 
MT2B1, MT2C_Mm) and LINE1 (Lx5, Lx3_Mus, L1Md_A, L1Md_F) repeat sequences. Proportions are calculated by dividing the number of DEGs by the total number of genes. J) Plot of the proportion of upregulated (blue) and downregulated (red) DEGs in Rap $1^{+/+}$ vs Rap1/ mESCs (FC > 1.5; FDR < 0.1) at fixed distances from MT2_Mm repeat sequences. 
A
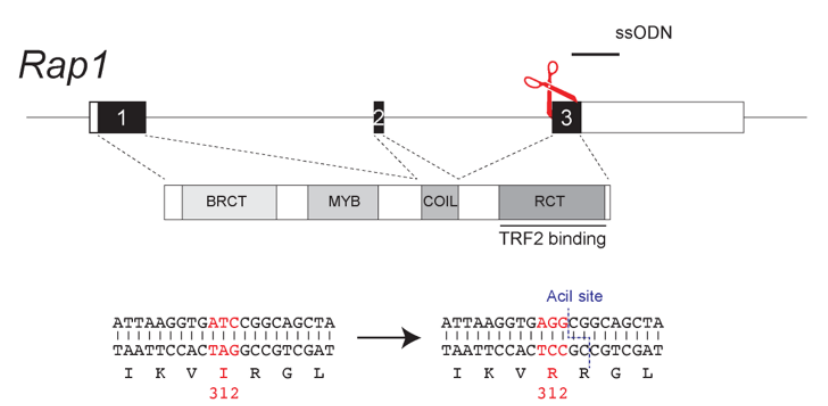

D

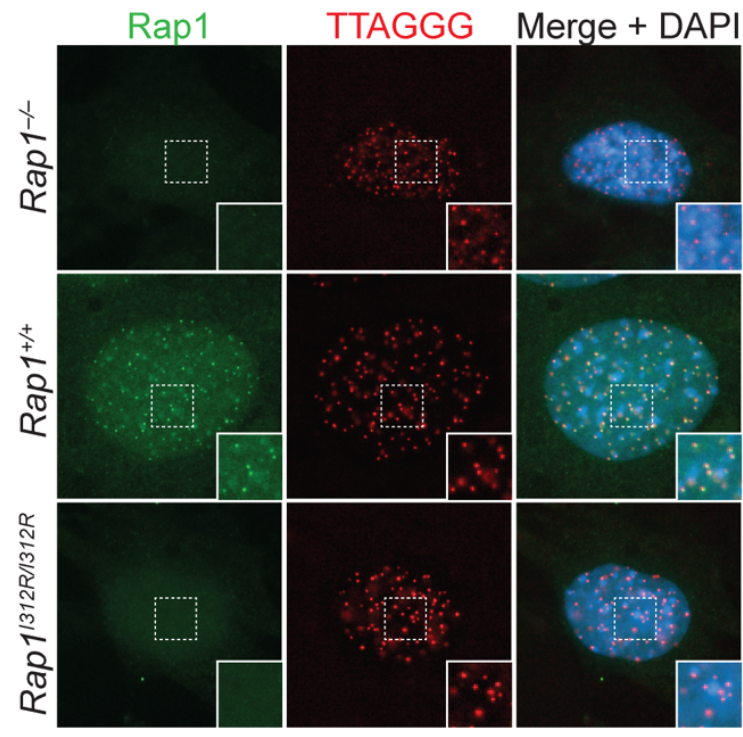

F

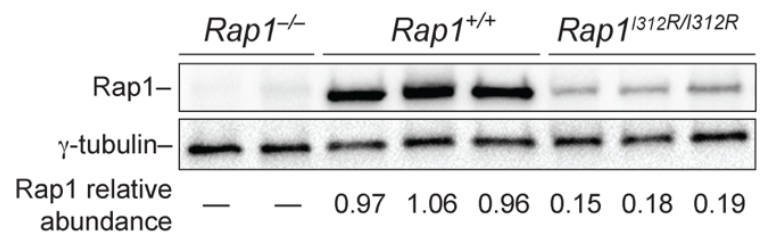

B

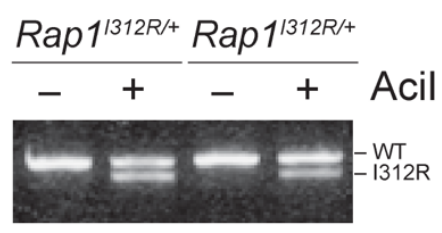

C

WT : ATTAAGGTGATCCGGCAGCTA I312R : ATTAAGGTGAGGCGGCAGCTA

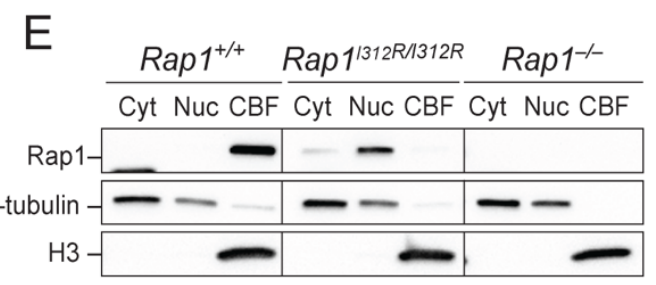

G

Differentially Expressed Genes $\left(\right.$ Rap 1/ vs Rap ${ }^{1+/}$, FC > 1.5, FDR < 0.1)

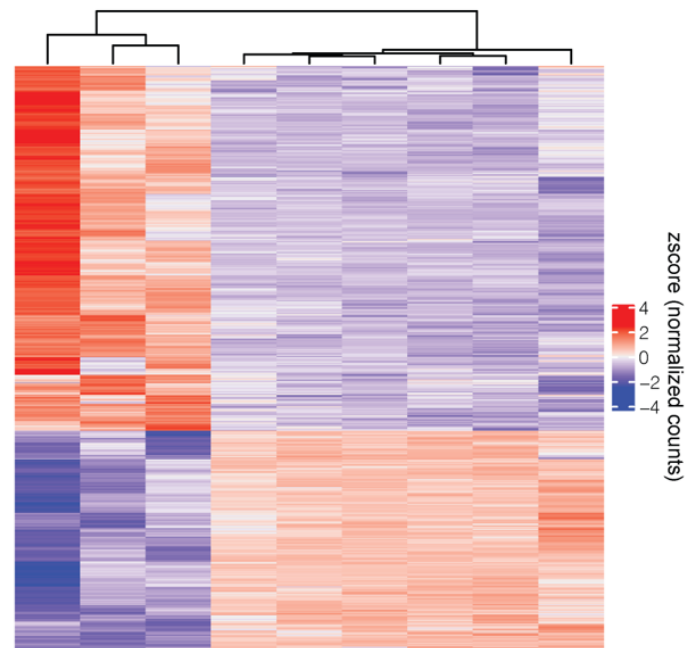

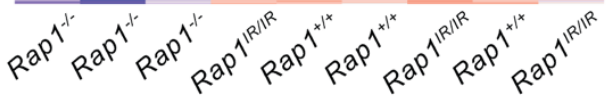


A

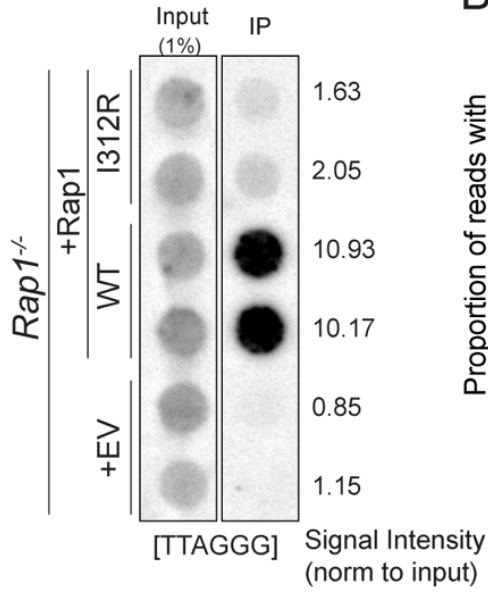

D
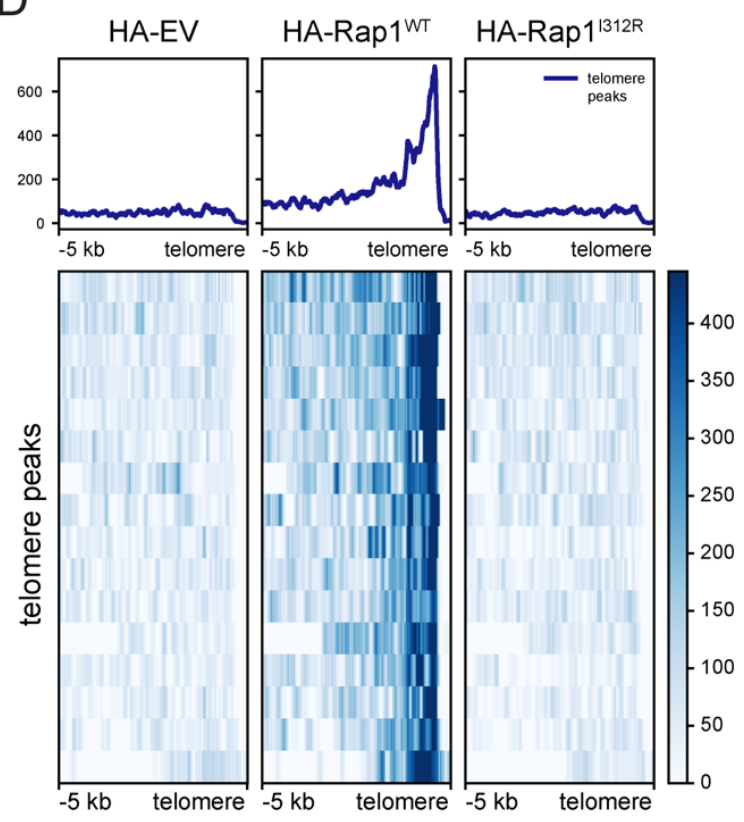

$\mathrm{F}$

His-

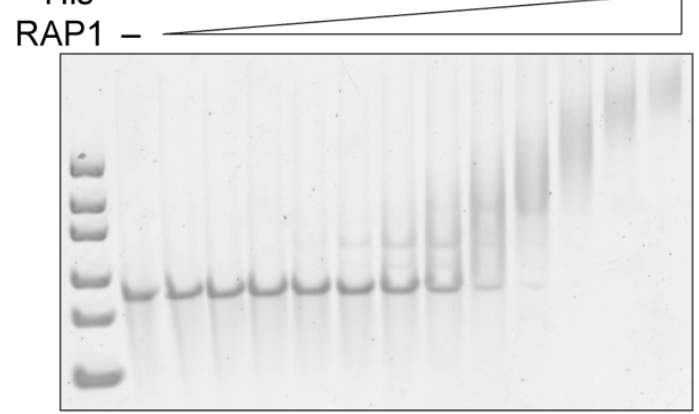

74bp [TTAGGG/AATCCC]

B

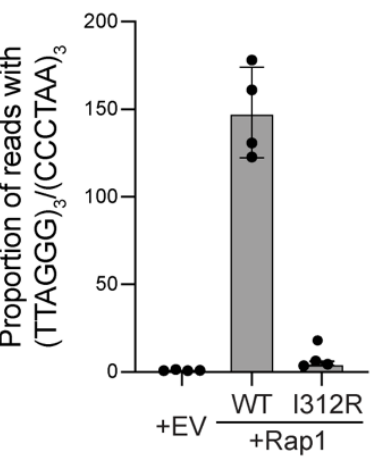

C

MACS2 Peak Calling $(q<0.05)$

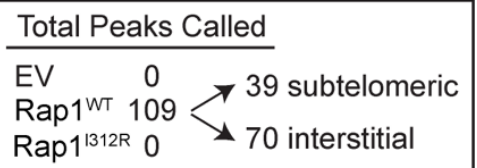

E
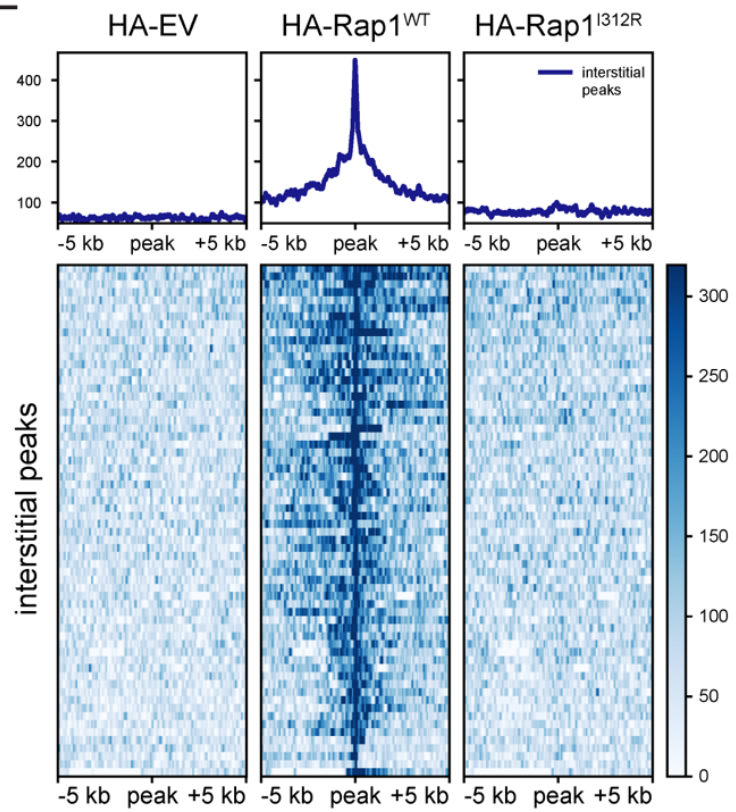

G

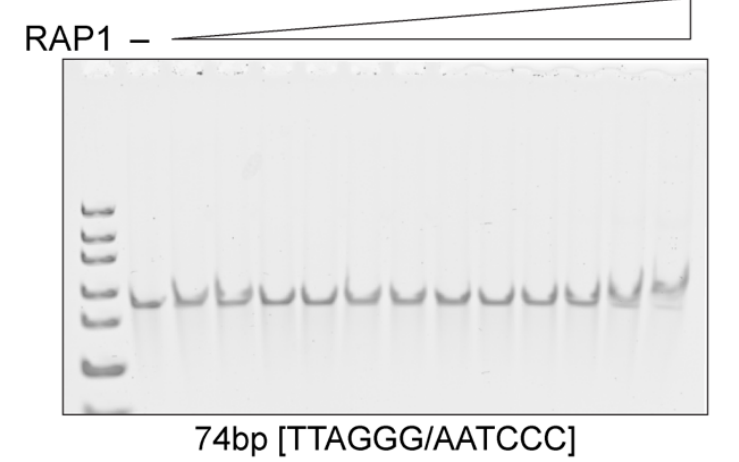


A

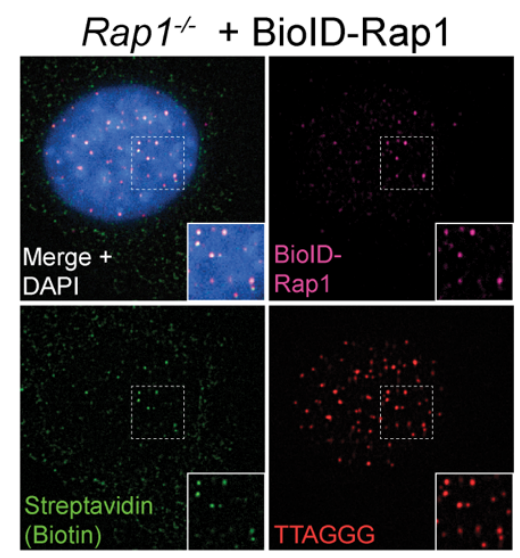

C

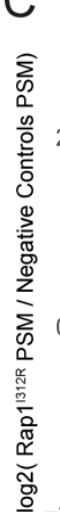

B

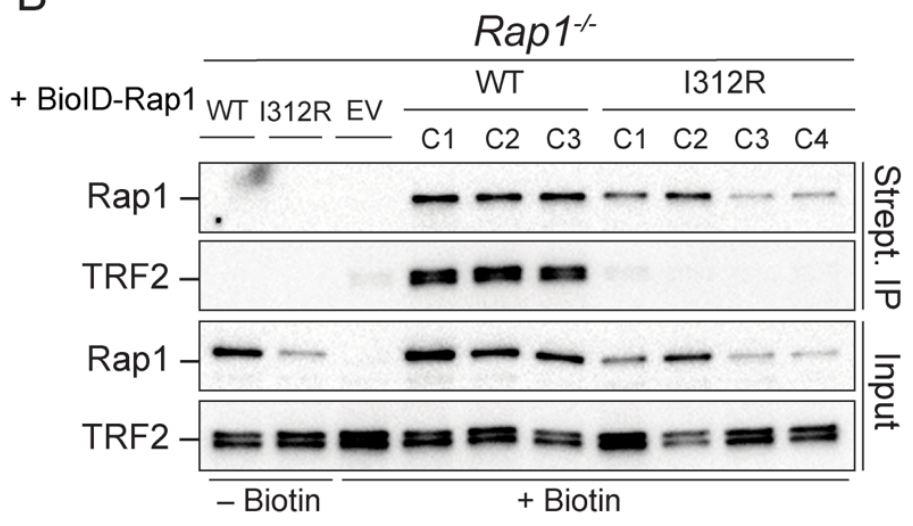

D

$\log 2$ ( Rap $1^{\text {Wr }}$ PSM / Negative Controls PSM )

- Not enriched

- Enriched in Rap1-WT

- Enriched in Rap1-I312R

- Enriched in Rap1-WT and I312R

2

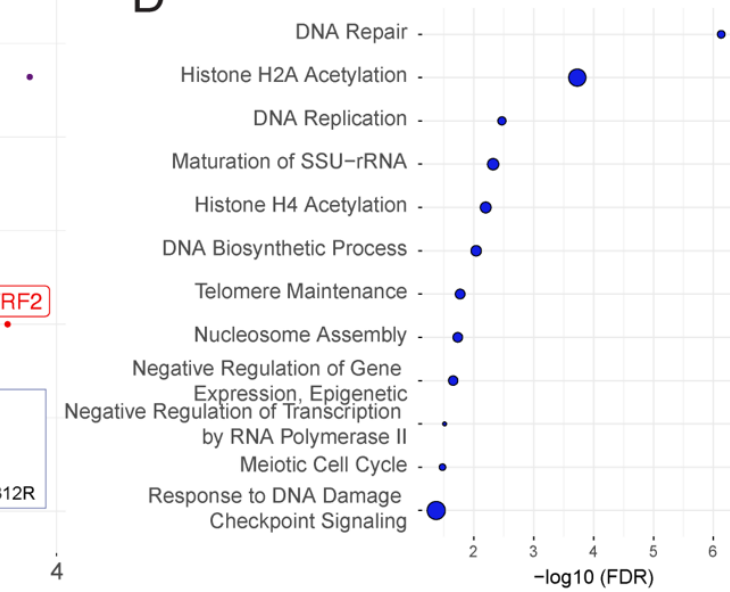

E

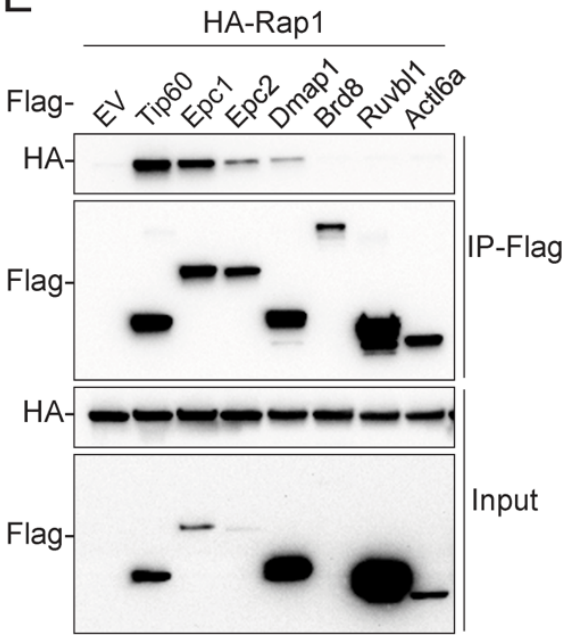

F

$G$

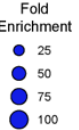

HA- EV RaP1-1312R RaP1-WT RaP1-1312R

Myc- EPC1 EPC2 TRF2 TRF2

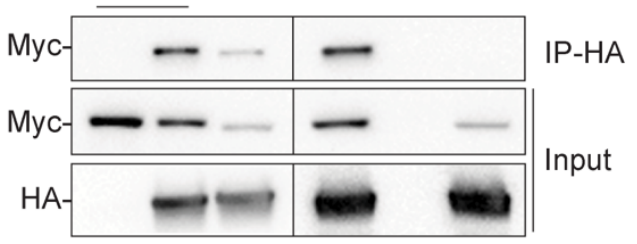

Myc-Tip60

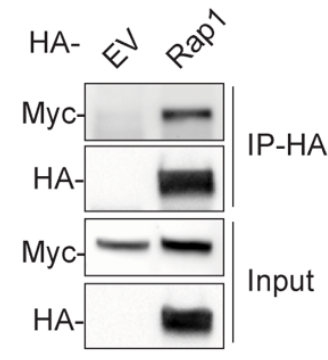




\section{Barry et al. Figure 4}

A

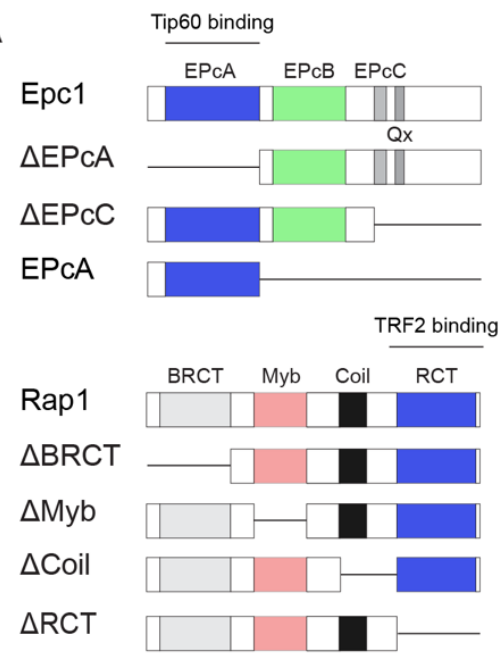

B

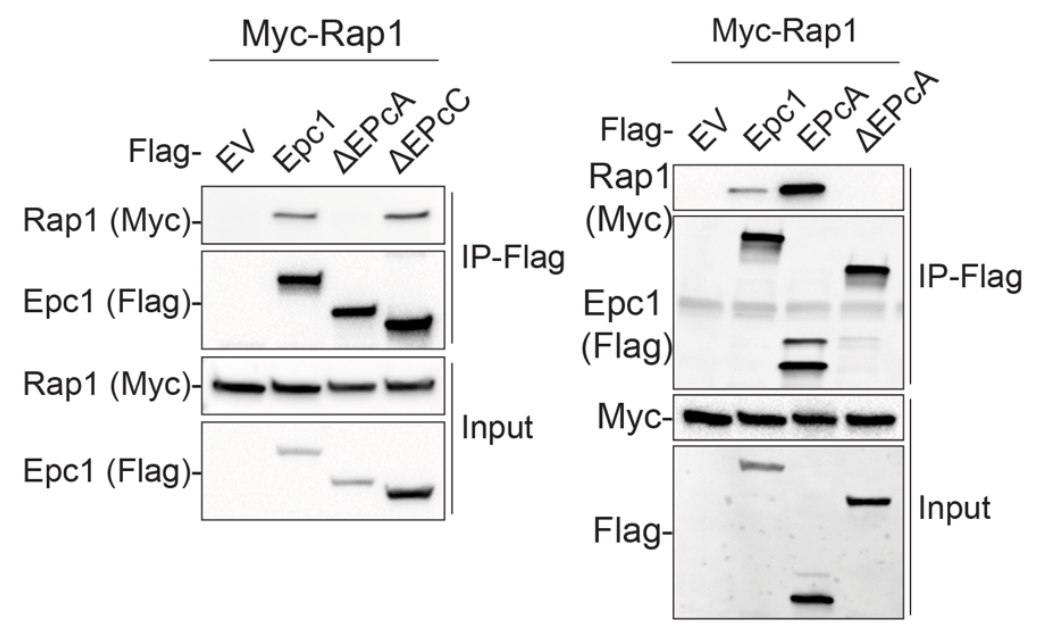

D

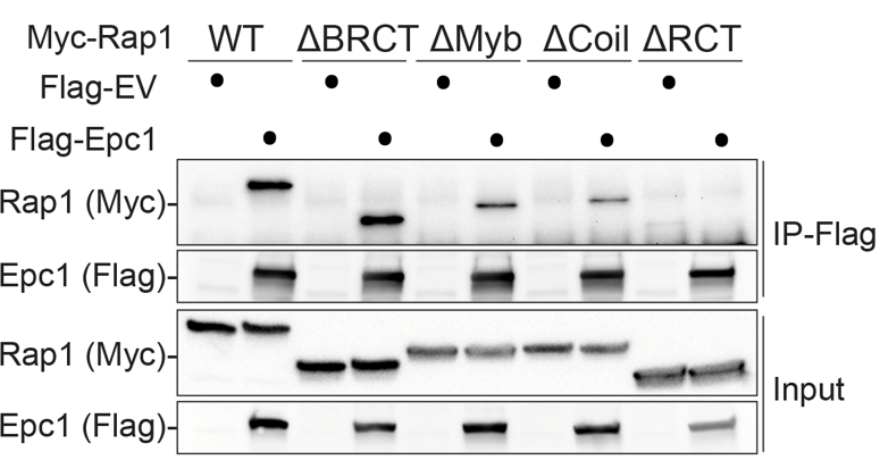

E Myc-Tip60 HA-Rap1 Flag-Epc1

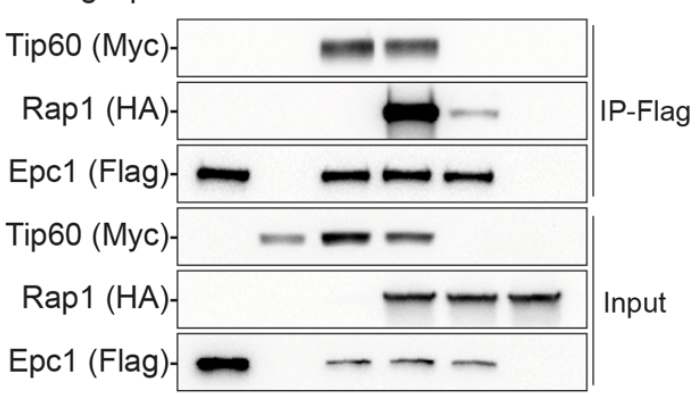

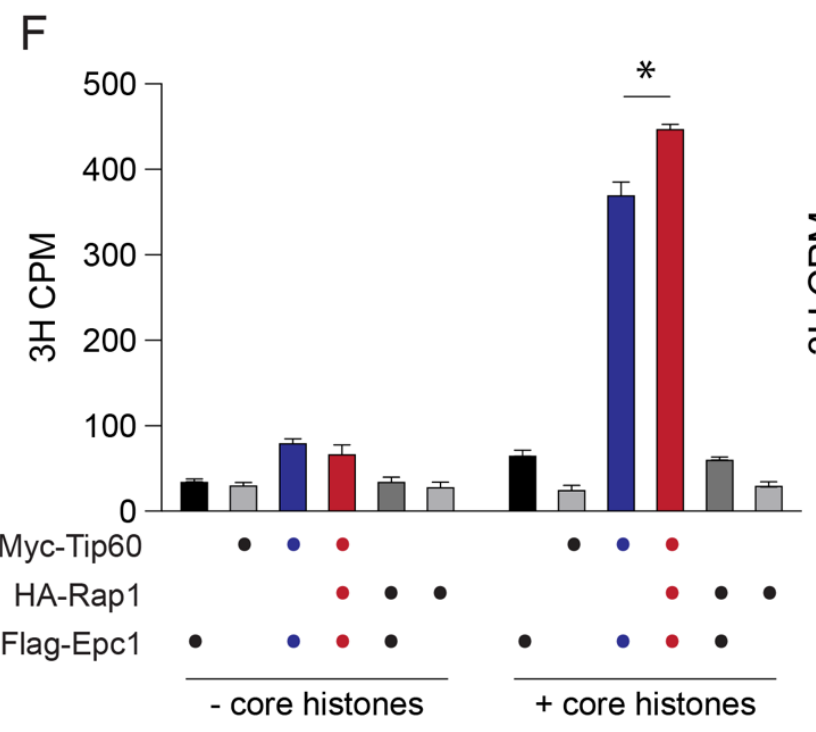

G

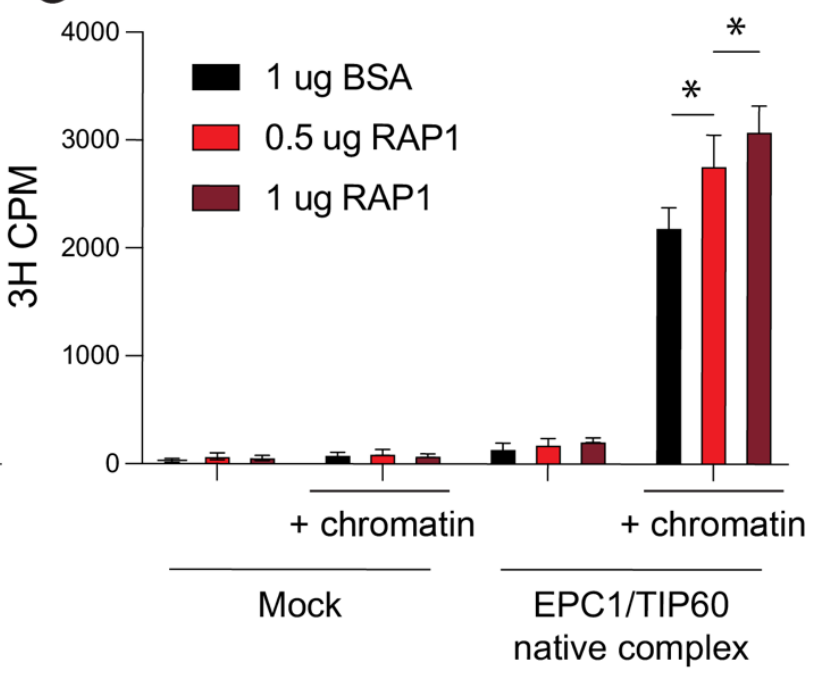


A

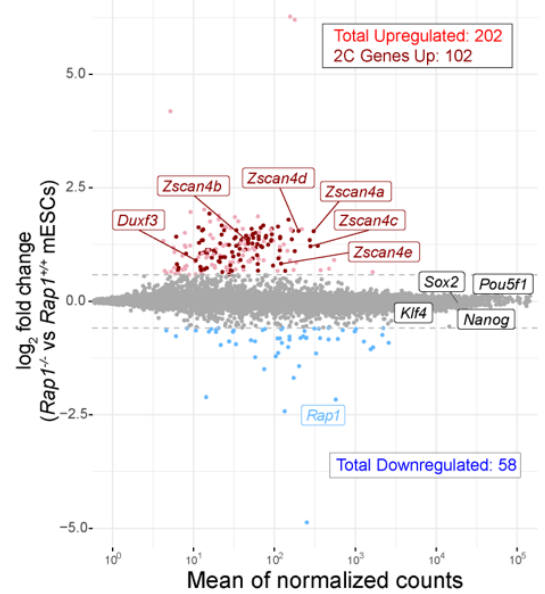

D $=\operatorname{Rap} 1^{1++}=\operatorname{Rap} 1^{\kappa}$

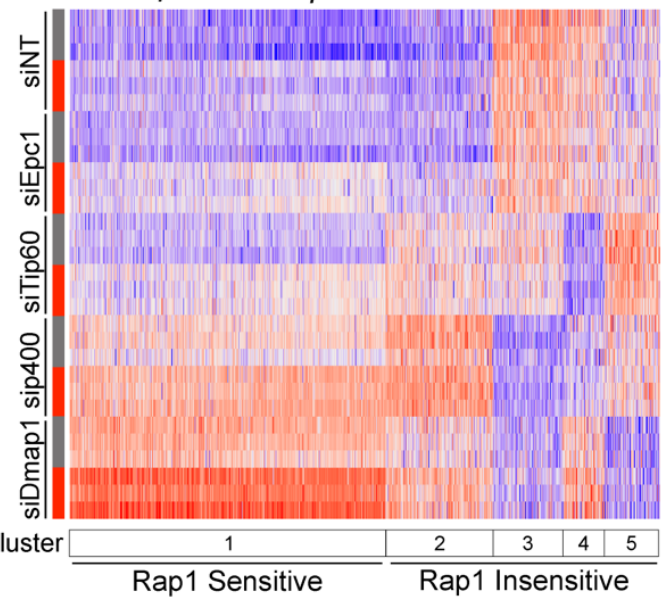

$\mathrm{F}$

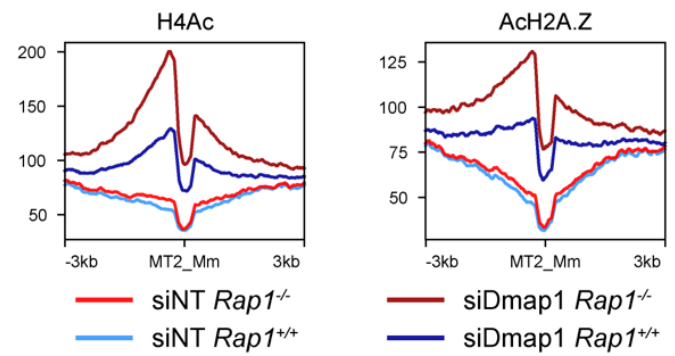

$\mathrm{H}$

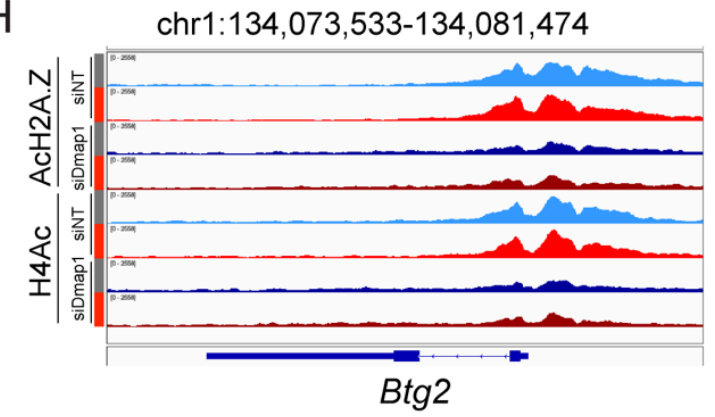

Barry et al. Figure 5

C $\left(\right.$ Rap $1 \%$ vs Rap $1^{+/+}$, FC > 1.5, FDR < 0.1)

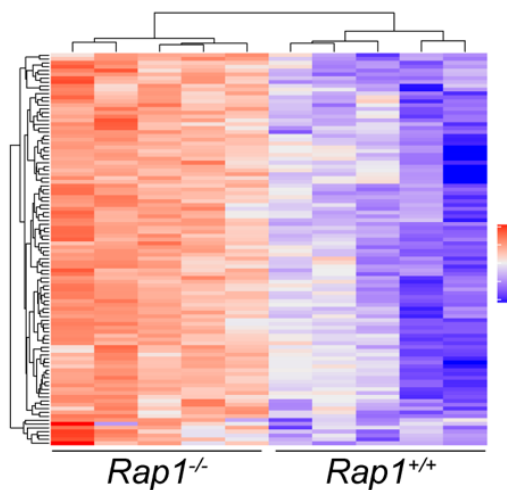

MT2_Mm

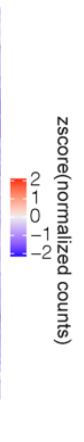

$E$

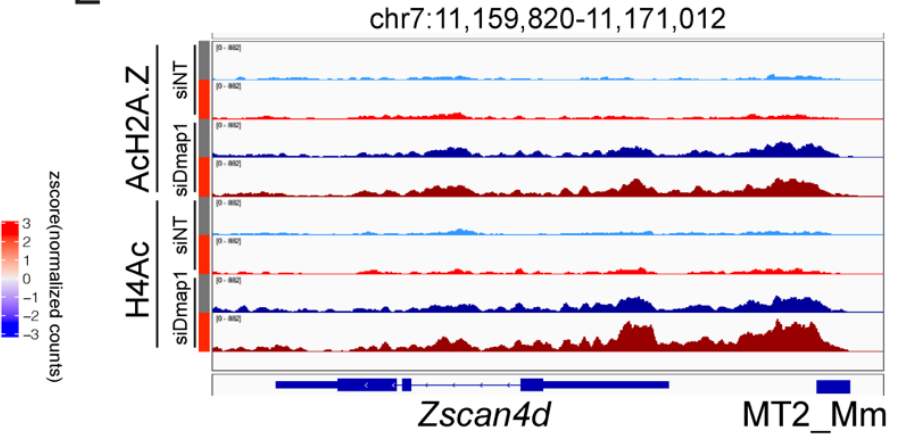

G
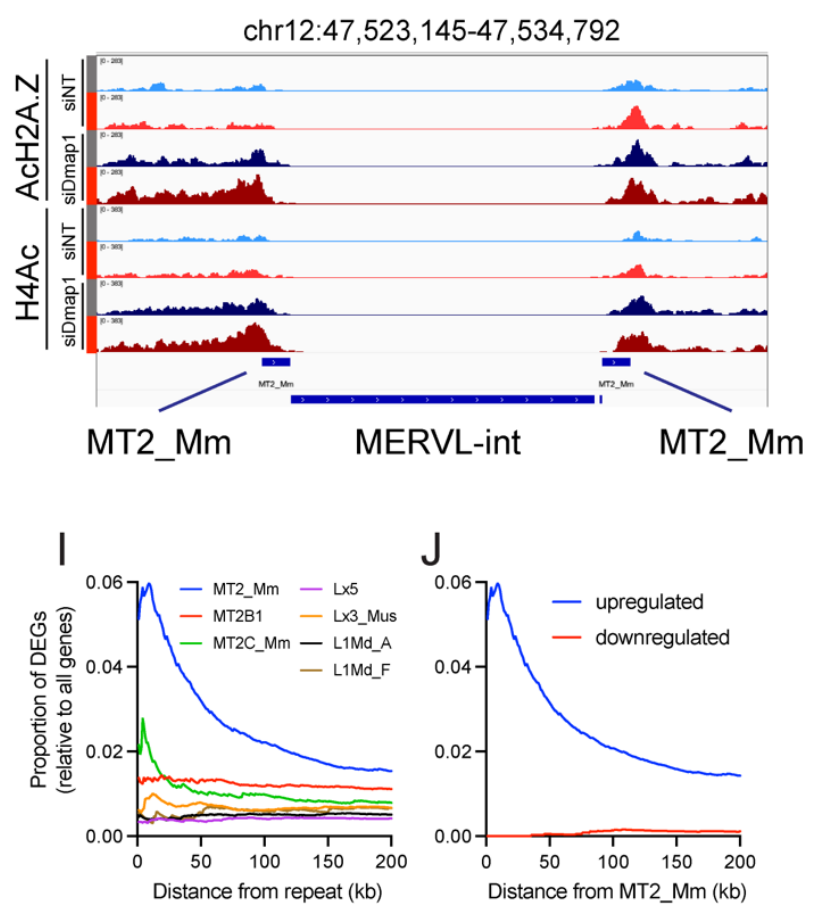


\section{Supplemental Figures}

\section{Barry et al. Figure S1}

A

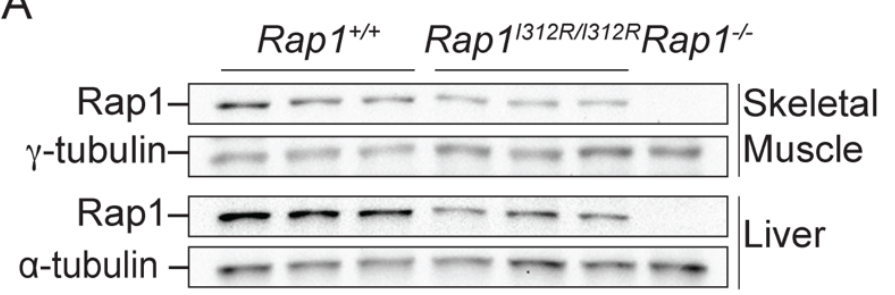

B

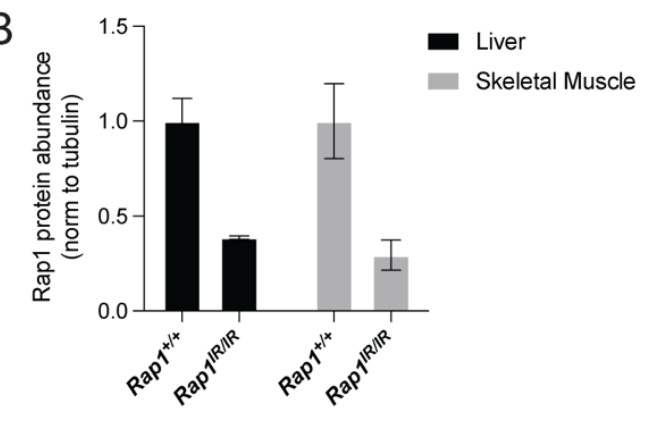

C

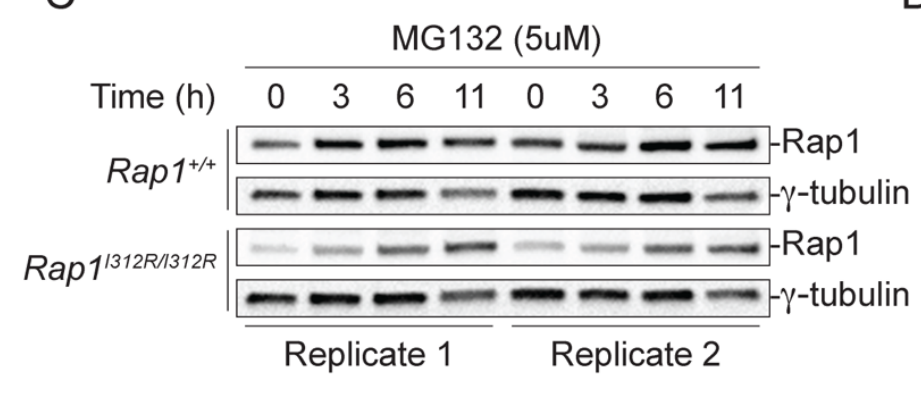

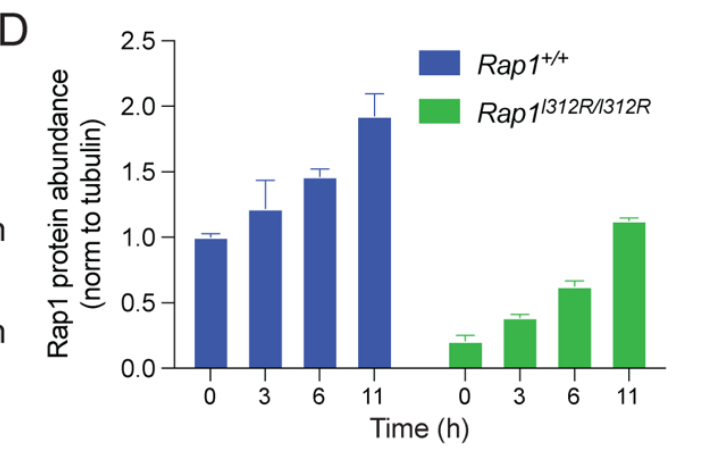

E
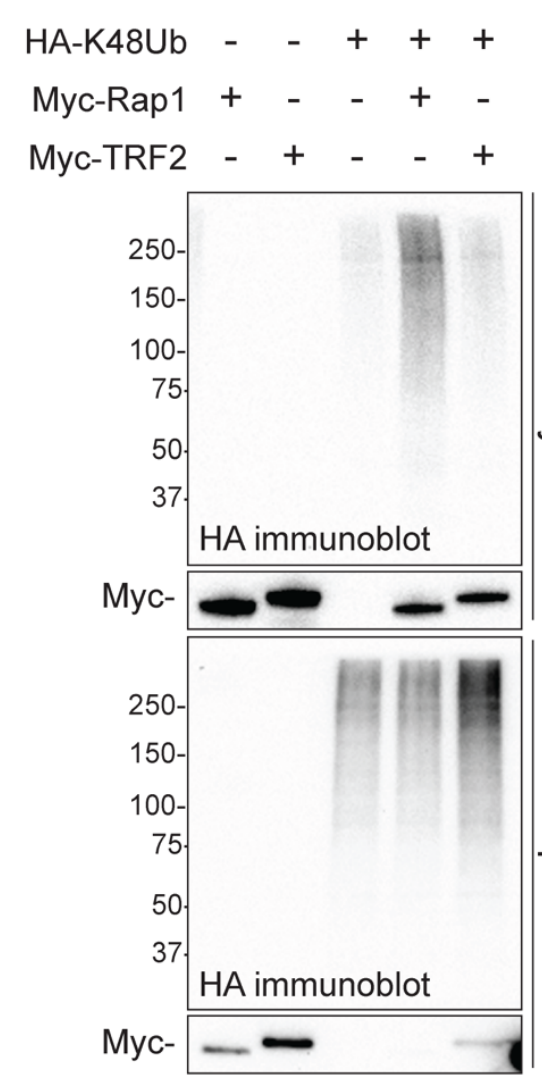

$\mathrm{F}$

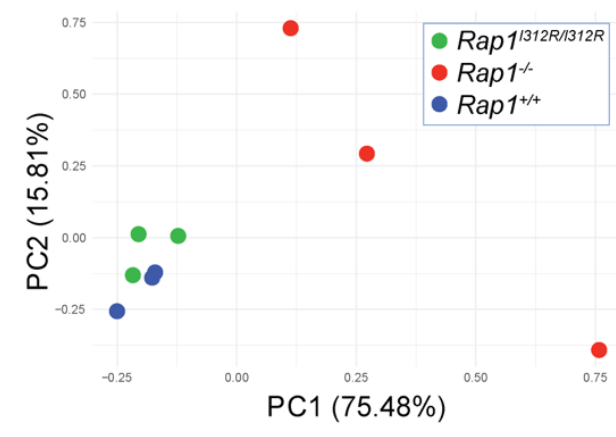

G

Retinal Ganglion Cell Axon Guidance . Collagen-Activated Tyrosine Kinase Receptor Signaling Pathway

Release of Cytochrome C From Mitochondria . Branching Involved in abyrinthine Layer Morphogenesis Hepatocyte Apoptotic Process .

Collagen-Activated Signaling Pathway .

흥 Lung growth .

Mesenchymal-Epithelial Cell Signaling .

Vascular Associated Smooth Muscle Cell Development Nephric Duct Development . 
Figure S1 related to Figure 1: Analysis of extratelomeric Rap1 protein level regulation and impacts on gene regulation. A) Immunoblot for Rap1 from $\operatorname{Rap} 1^{-\%}(\mathrm{n}=$ 1), $\operatorname{Rap}^{+/+}(\mathrm{n}=3)$, and $\operatorname{Rap} 1^{1312 R / 1312 R}(\mathrm{n}=3)$ mouse skeletal (gastrocnemius) muscle and liver lysates. $\gamma$ - or $\alpha$-tubulin are used as loading controls. B) Quantification of Rap1 levels in (A) Rap1 relative abundance was determined by normalizing to $\gamma$ - or $\alpha$-tubulin, as indicated. Data is the mean \pm standard deviation of $n=3$ biological replicates. C) Immunoblot for Rap1 from Rap $1^{+/+}$and $R a p 1^{1312 R / 312 R}$ MEFs ( $\mathrm{n}=2$ biological replicates) following treatment with proteasome inhibitor MG132 (5uM) for 11 hours. $\gamma$-tubulin is used as loading control. D) Quantification of Rap1 levels in C. Rap1 relative abundance was determined by normalizing to $\gamma$-tubulin. Data is the mean \pm standard deviation of $n=2$ biological replicates. E) ColP of Myc-tagged Rap1, TRF2, and HA-K48-linked ubiquitin (K48Ub) in co-transfected HEK293T cells. F) Principal component analysis (PCA) of RNA-seq data from $R a p 1^{+/+}$, Rap1/312R//312R, and Rap1/- MEFs. Percent along axes indicate the proportion of variance due to the indicated principal component. G) Graphical representation of top 10 biological processes overrepresented in differentially expressed genes (DEGs) between Rap $1^{+/+}$and Rap1/- MEFs (FC > 1.5; FDR < 0.1) using PANTHER Classification System statistical overrepresentation test. 
A

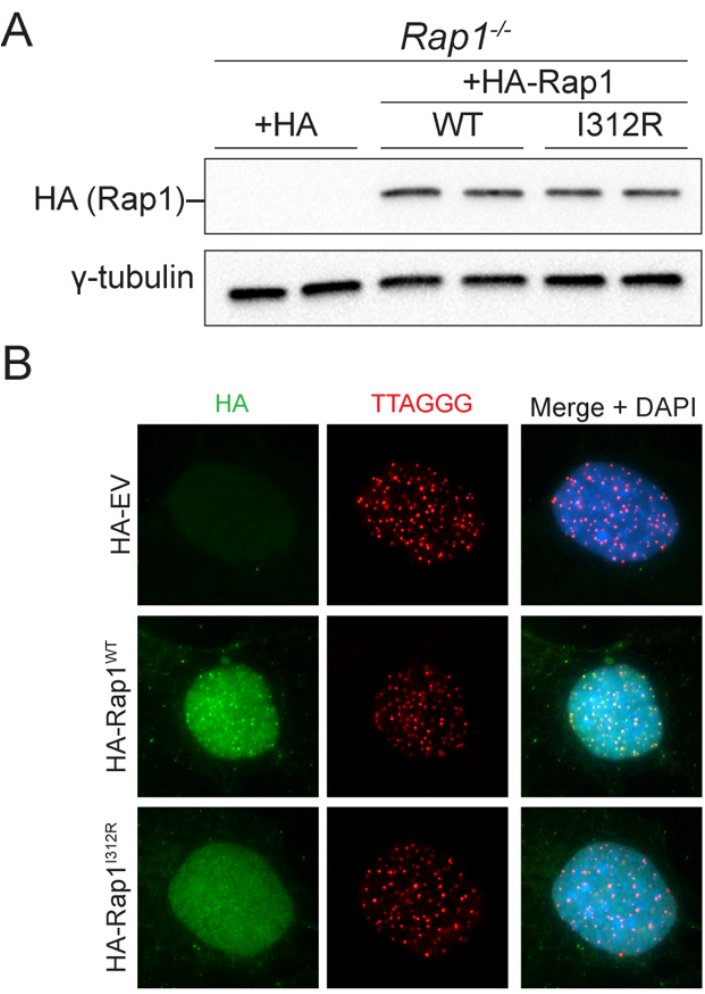

E

His-

RAP1 -

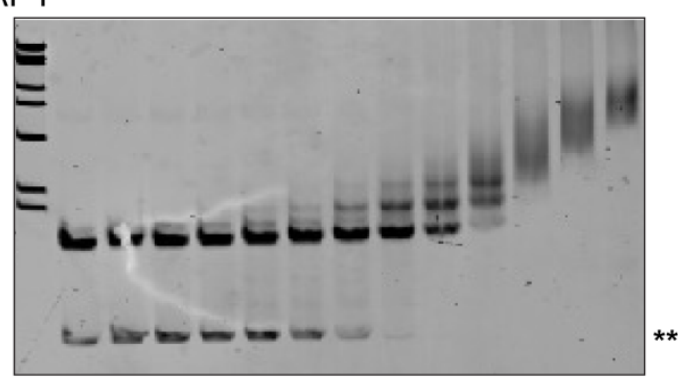

F

\section{Nucleosome}

His-

RAP1 -

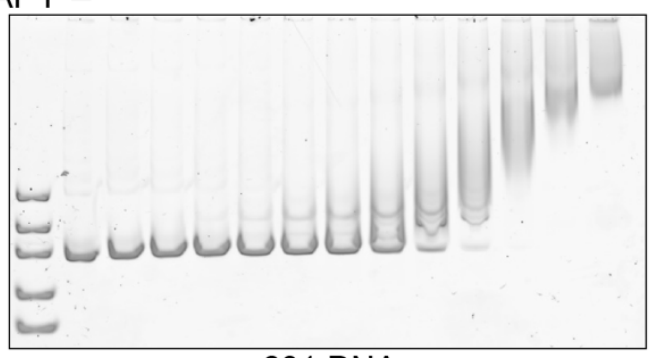

601 DNA
C

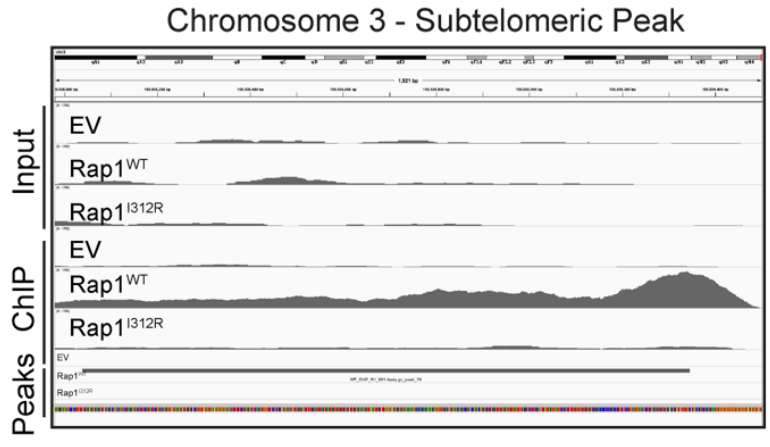

D

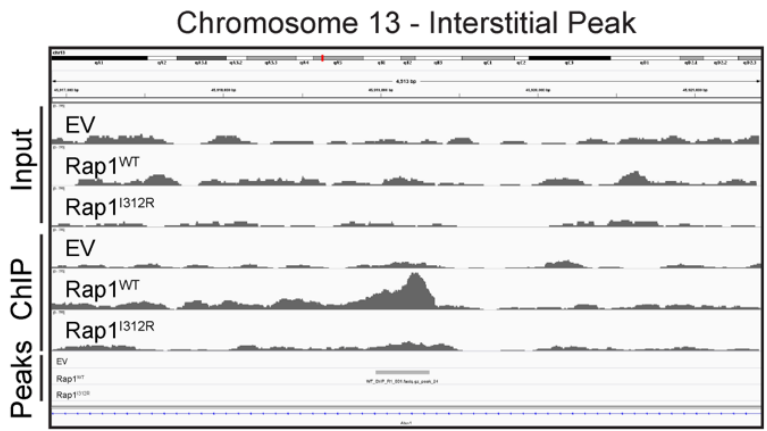

$G$

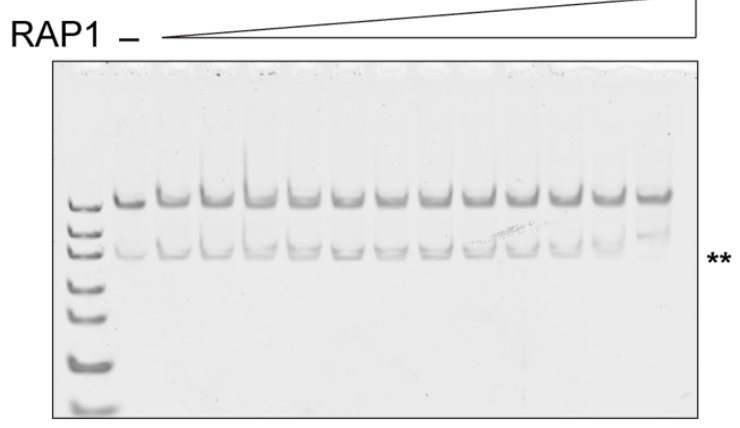

$\mathrm{H}$

\section{Nucleosome}

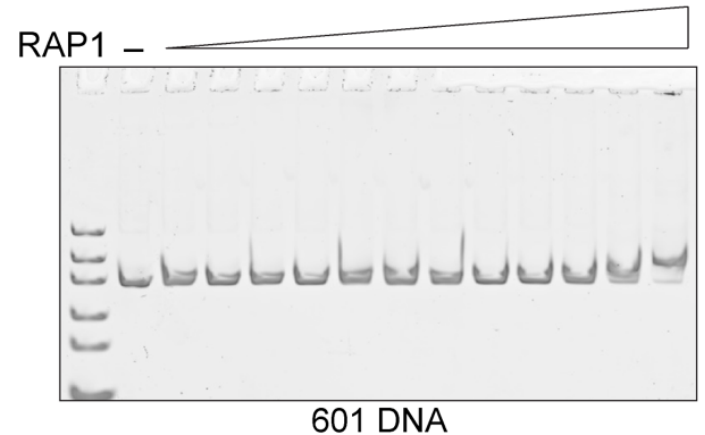


Figure S2, related to Figure 2: Analysis of Rap1 chromatin and DNA binding activity using ChIP-seq and EMSA. A) Immunoblot for Rap1 (anti-HA antibody) in Rap1 1/ MEFs expressing HA-Rap1-WT, HA-Rap1-I312R, or empty vector (EV) control ( $n=2$ biological replicates). $\gamma$-tubulin is used as loading control. B) Representative IF-FISH image in Rap11- MEFs expressing HA-Rap1-WT, HA-Rap1-I312R, and empty vector (EV) control and stained for Rap1 (anti-HA antibody green) and telomeres (TTAGGG PNA probe in red). DAPI (blue) is used as counterstain. C) HA-ChIP-Seq profile at representative HA-Rap1WT subtelomeric peak on chromosome 3. Profiles plotted are representative of $n=4$ biological replicates. D) HA-ChIP-Seq profile at representative HA-Rap1-WT interstitial peak on chromosome 13. E) Electrophoretic mobility shift assay (EMSA) using His-tagged Rap1 and affinity purified nucleosome substrate. ${ }^{* *}$ free DNA found in nucleosome preparations. F) EMSA using non-His-tagged Rap1 and purified nucleosome. G) EMSA using His-tagged Rap1 and double-stranded 601 DNA substrate. H) EMSA using nonHis-tagged Rap1 and double-stranded 601 DNA substrate. 
A
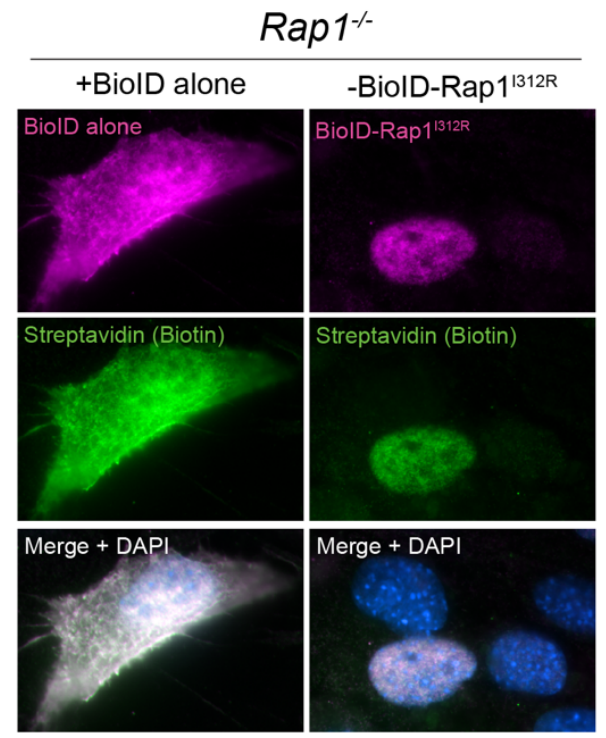

B
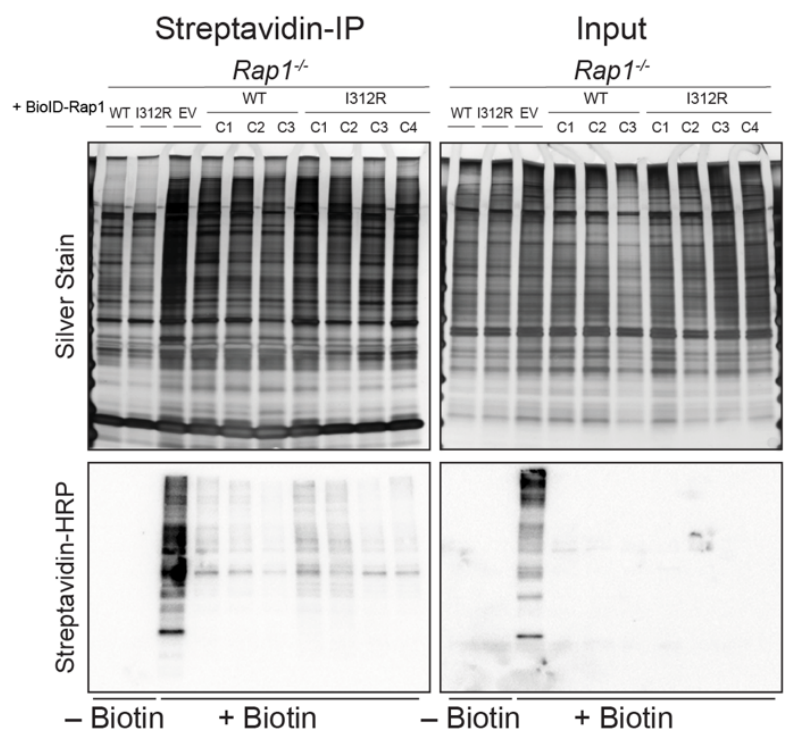

C

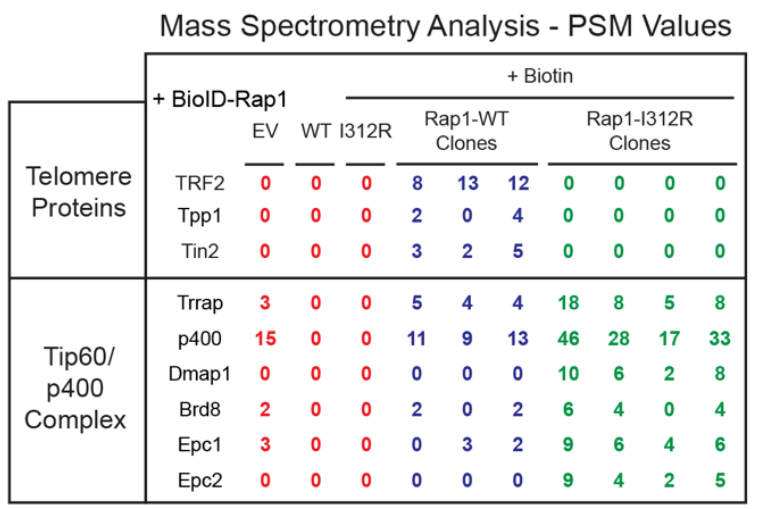

$\mathrm{E}$

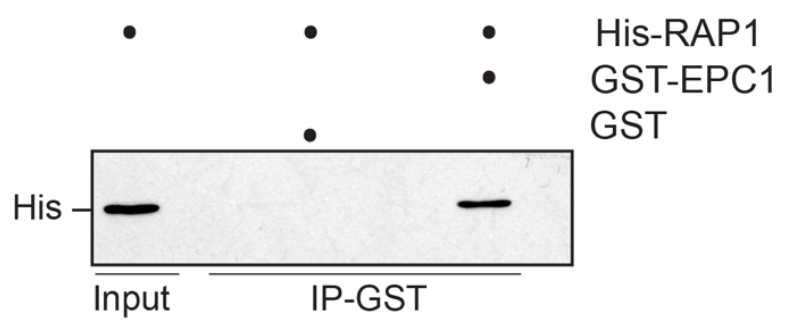

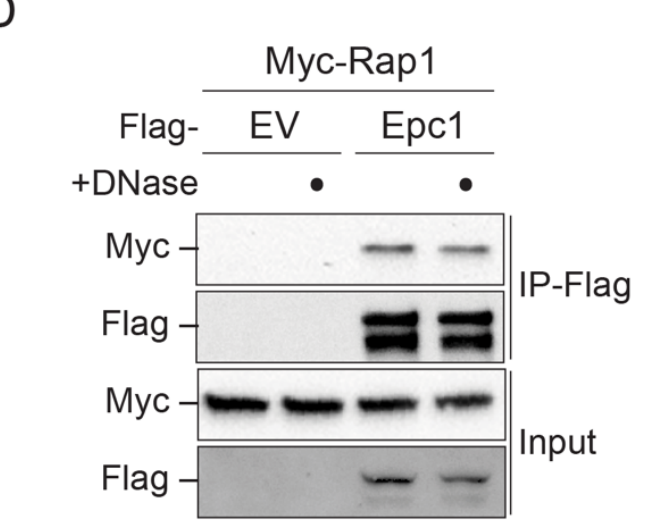

Figure S3, related to Figure 3: Analysis of Rap1 protein interactors by proximitydependent biotinylation. A) Representative images of streptavidin-IF in Rap1/- MEFs expressing BiolD-Rap1-I312R and empty vector (EV) control for BiolD (anti-FLAG; 
magenta) and biotin (streptavidin antibody in green). DAPI (blue) is used as counterstain. B) Silver stain (top) and Western blot for streptavidin-HRP (bottom) following streptavidin pull-down in Rap1/- MEFs expressing BiolD-Rap1-WT ( $\mathrm{n}=3$ biological replicates; clones C1, C2, C3), BiolD-Rap1-I312R ( $n=4$ biological replicates; clones C1, C2, C3, C4), and BiolD alone (EV). Where indicated, cells were treated with biotin $(50 \mu \mathrm{M})$ for 24 hours prior to harvest. C) Summary of peptide-spectrum match (PSM) values of telomere proteins (top) and Tip60/p400 complex members (bottom) from BiolD mass spectrometry analysis. D) CoIP of Flag-Epc1 and Myc-Rap1 following co-transfection of HEK293T cells. Where indicated, lysates were treated with DNase $(10 \mu \mathrm{g} / \mathrm{mL})$ for $1 \mathrm{hr}$ at room temperature prior to incubation with antibody for IP. E) Pull-down of GST-EPC1 and HisRAP1 using glutathione-coupled beads. GST tag alone is used as negative control. Blot is representative of $n=2$ technical replicates. 
A

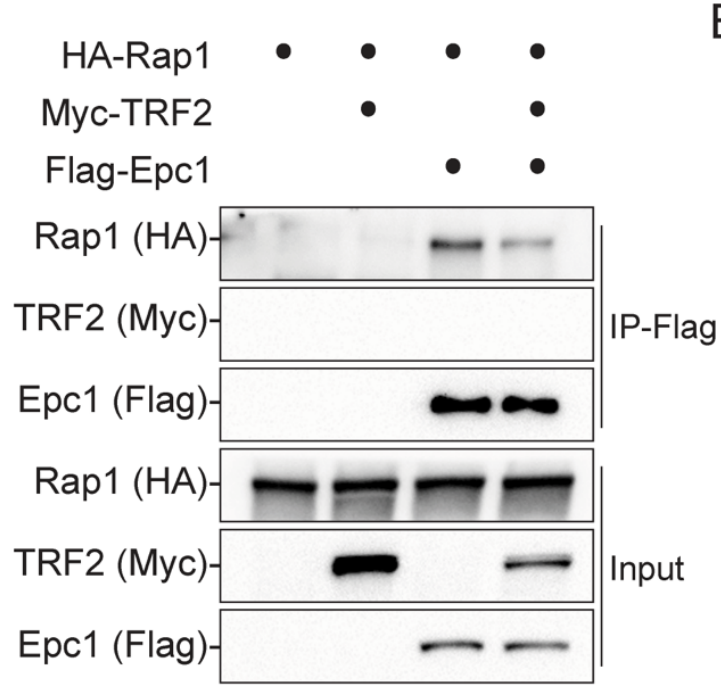

C

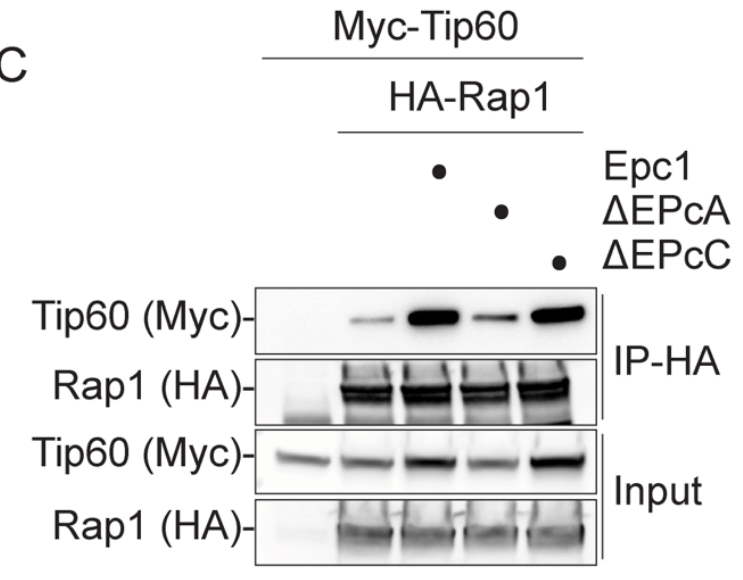

B

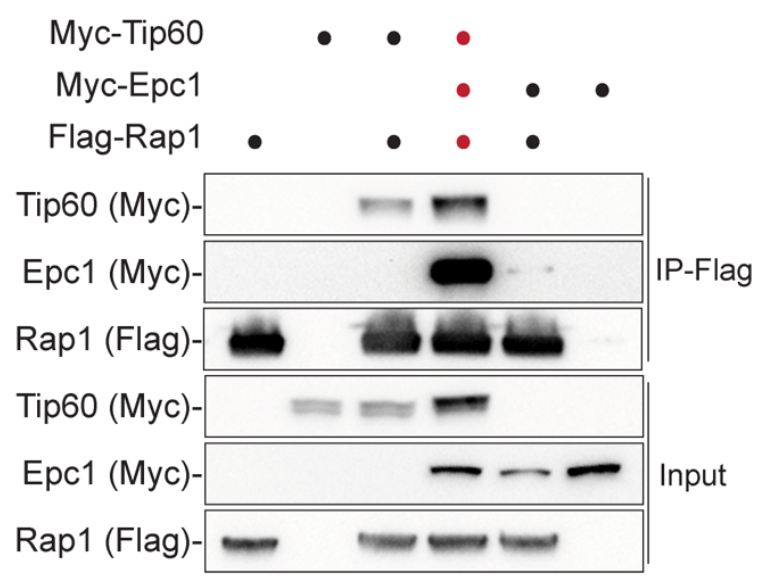

$\mathrm{D}$

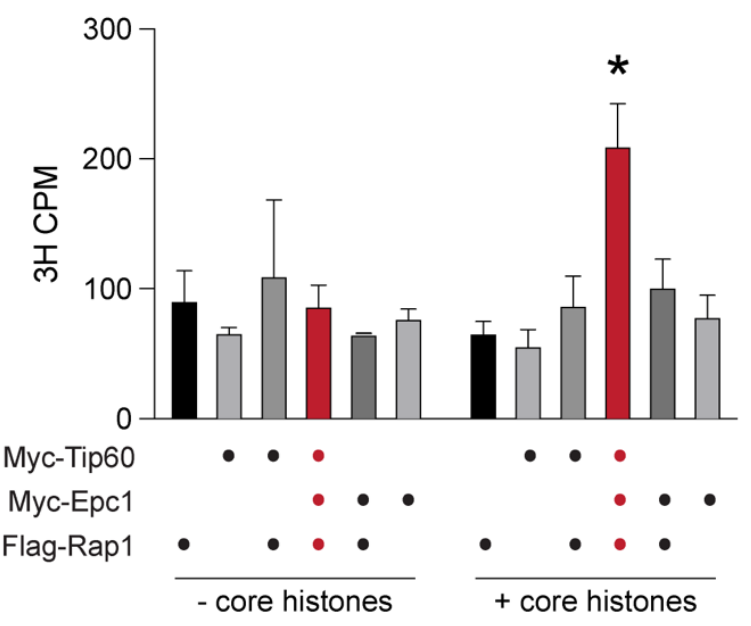

Figure S4, related to Figure 4: Biochemical analysis of Rap1 binding to Epc1 and Tip60. A) ColP of Flag-Epc1 and HA-Rap1 +/- Myc-TRF2 from HEK293T cells cotransfected with the indicated plasmid. B) ColP of Flag-Rap1, Myc-Epc1, and MycTip60. C) ColP of HA-Rap1, Myc-Tip60, and Epc1 deletion mutants. D) Histone acetyltransferase (HAT) activity assays using ColPs from $B$ and core histones. Data 
bioRxiv preprint doi: https://doi.org/10.1101/2021.11.02.467017; this version posted November 3, 2021. The copyright holder for this preprint (which was not certified by peer review) is the author/funder. All rights reserved. No reuse allowed without permission.

presented as the counts per minute (CPM) mean \pm standard deviation of $n=2$ technical replicates; two-way ANOVA, Tukey's multiple comparison test; * $p$-value $<0.01$. 
A

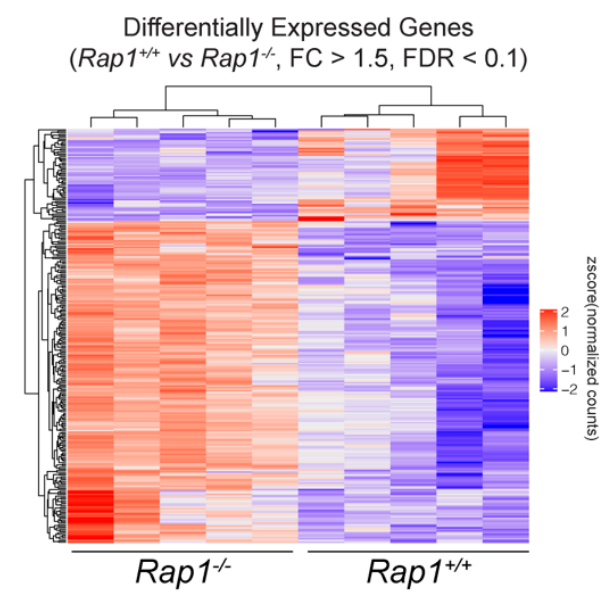

C

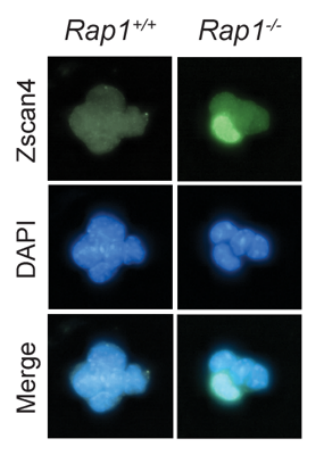

$E$

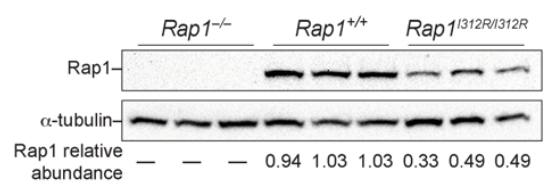

B
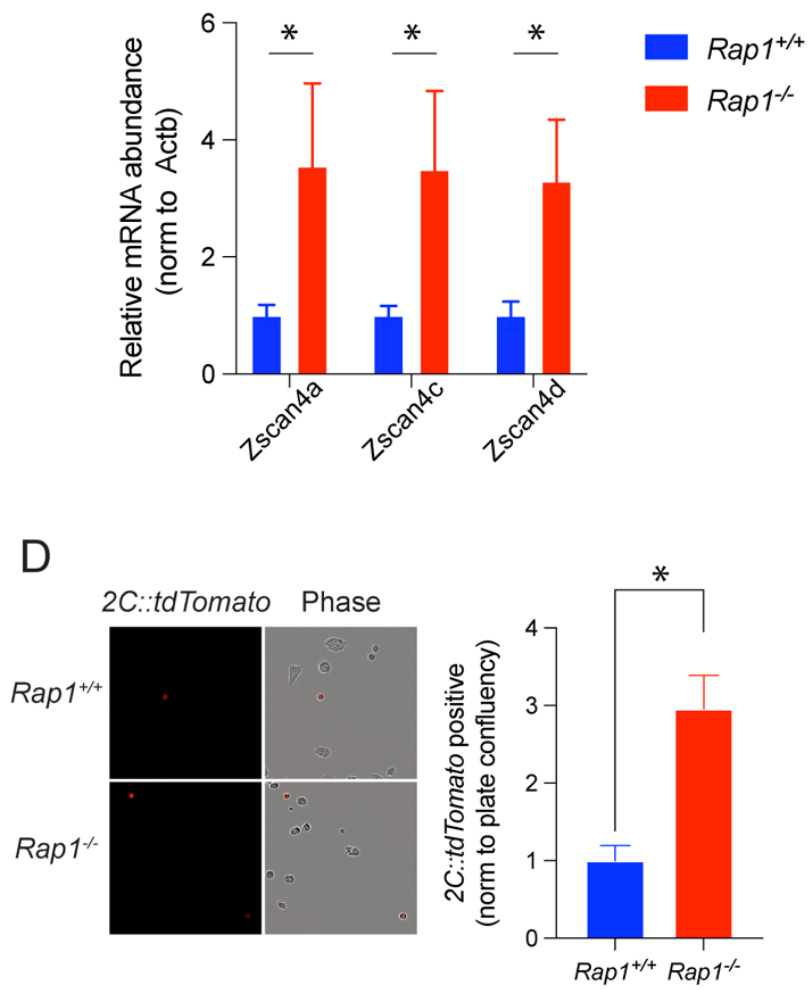

G

Differentially Expressed $2 \mathrm{C}$ Genes $\left(\operatorname{Rap}^{1^{+/}}{ }^{\text {vs }}\right.$ Rap $\left.1^{-/}, \mathrm{FC}>1.5, \mathrm{FDR}<0.1\right)$

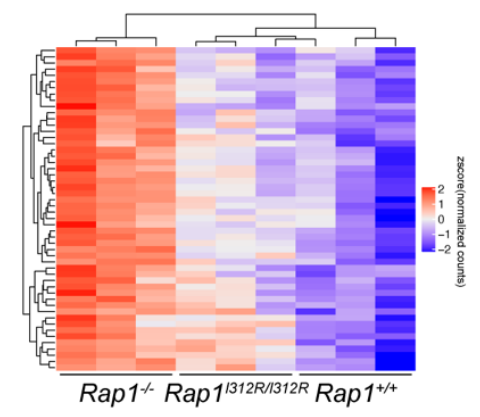

Figure S5 related to Figure 5: Analysis of transcriptomes and 2C-like state in $R a p 1^{+/+}$, Rap $1^{-/}$, and $\operatorname{Rap} 1^{1312 R / 312 R}$ mESCs. A) Hierarchically clustered heatmap representing RNA-seq data for differentially expressed genes (DEGs) between Rap1+/+ and $\operatorname{Rap}^{-/-}$mESCs (FC $>1.5 ; \mathrm{FDR}<0.1 ; \mathrm{n}=5$ biological replicates per genotype). B) qRT-PCR for Zscan4 locus (Zscan4a, Zscan4c, Zscan4d) in Rap $1^{+/+}$and Rap $1^{-/-}$mESCs. 
Relative mRNA abundance is determined by normalizing to ACTB using the delta-delta Ct method. Data are mean \pm standard deviation of $n=3$ biological replicates; student's $T$ test; * p-value < 0.05. C) (Left) Representative images of IF for Zscan4 (green) in Rap1 ${ }^{+/+}$ and Rap $1^{-/}$mESCs. DAPI (blue) is used as counterstain. (Right) Percent of Zscan4 positive cells in $R a p 1^{+/+}$and Rap1/- mESCs. Data are mean \pm standard deviation of $n=3$ biological replicates; student's T test; ${ }^{*} p$-value < 0.01. D) (Left) Representative images of live-cell imaging for $2 \mathrm{C}:$ :tdTomato reporter (red) in Rap $1^{+/+}$and Rap $1^{1 /-} \mathrm{mESC}$. Phase contrast imaging is used to determine cell confluency. (Right) Relative number of 2C::tdTomato positive cells in Rap $1^{+/+}$and $R a p 1^{-/-}$mESCs normalized to confluency. Data are mean \pm standard deviation of $n=3$ biological replicates; student's $T$ test; * $p$-value $<$ 0.01. E) Immunoblot for Rap1 from Rap $1^{-/}, \operatorname{Rap}^{+/+}$, and Rap $1^{1312 R / 312 R} \mathrm{mESC}$ whole cell lysates ( $n=3$ biological replicates). Rap1 relative abundance was determined by normalizing to $\alpha$-tubulin. F) qRT-PCR for 2C genes (Zscan4c, Dux, Gm6763) and MERVL in $R a p 1^{+/+}$, Rap $1^{-/}$, and $R a p 1^{1312 R / 312 R}$ mESCs. Relative mRNA abundance is determined by normalizing to ACTB using the delta-delta Ct method. Data are mean \pm standard deviation of $n=3$ biological replicates; 2-way ANOVA, Dunnett's multiple comparison test; * $p$-value < 0.05. G) Hierarchically clustered heatmap representing RNA-seq data for differentially expressed $2 \mathrm{C}$ genes between $\operatorname{Rap} 1^{1 /+}$ and $\operatorname{Rap} 1^{-/-}$mESCs $(\mathrm{FC}>1.5$; FDR $<$ $0.1 ; n=3$ biological replicates). 
A
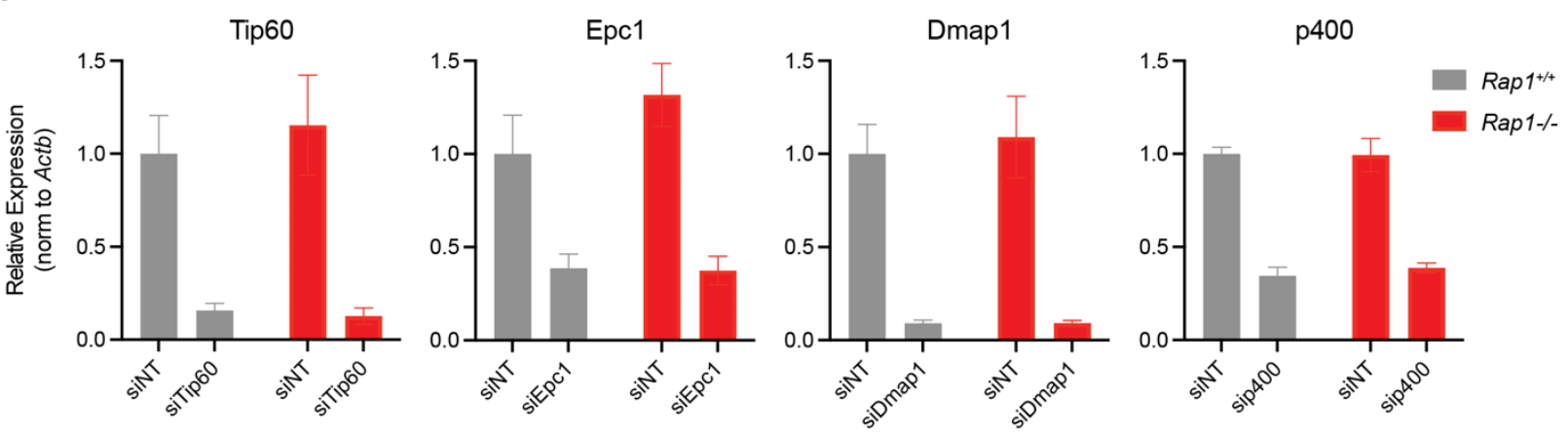

B

C
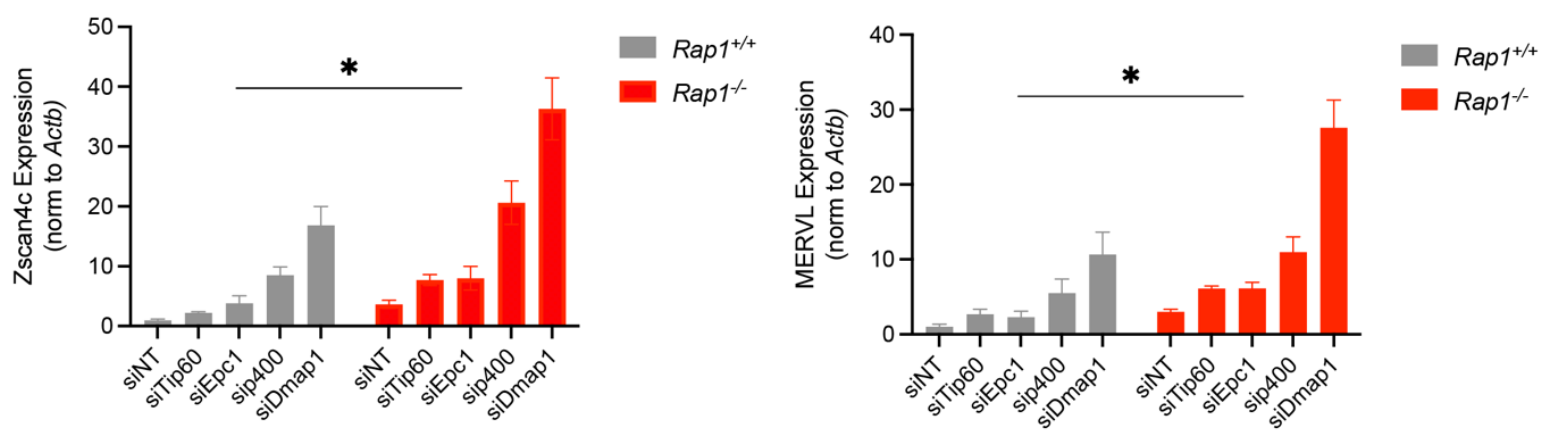

Figure S6 related to Figure 5: Investigating the interplay between Rap1 and Tip60/p400 on 2C gene transcription. A) qRT-PCR for the indicated gene in Rap1 $1^{+/+}$ and Rap $1^{-/}$mESCs treated with the indicated siRNA or nontargeting (siNT) control. Relative mRNA abundance is determined by normalizing to ACTB using the delta-delta Ct method. Data are mean \pm standard deviation of $n=3$ biological replicates. B) qRTPCR for Zscan4c in $R a p 1^{+/+}$and Rap1\% $1^{-/}$mESs treated with the indicated siRNA or nontargeting (siNT) control. Relative mRNA abundance is determined by normalizing to ACTB using the delta-delta Ct method. Data are mean \pm standard deviation of $n=3$ biological replicates; student's T test; * $p$-value $<0.05$. C) qRT-PCR for MERVL in Rap $1^{+/+}$ and Rap $1^{-/}$mESCs treated with the indicated siRNA or nontargeting (siNT) control. Relative mRNA abundance is determined by normalizing to ACTB using the delta-delta 
bioRxiv preprint doi: https://doi.org/10.1101/2021.11.02.467017; this version posted November 3, 2021. The copyright holder for this preprint (which was not certified by peer review) is the author/funder. All rights reserved. No reuse allowed without permission.

Ct method. Data are mean \pm standard deviation of $n=3$ biological replicates; student's $T$ test; * $\mathrm{p}$-value $<0.05$ 


\section{Methods}

\section{Animal Studies}

Rap 1 knockout mice were generated by crossing the Rap 1 floxed allele to Rosa-Cre mice, as previously described (Sfeir et al. 2010). Rap $1^{1312 R}$ knock-in mice were generated by CRISPR/Cas9 editing via injection of fertilized oocytes with Cas9 mRNA, sgRNA targeting the Rap1 locus (5'-TAGCTGCCGGATCACCTTAA-3'), and single-stranded DNA donor (ssODN) carrying the mutated allele (Supplementary Table S6). Two mice heterozygous for the mutation were obtained using this method and were crossed to produce homozygous mice. Genotyping was performed using the following primers: Fwd: 5'CTCTCACACACACACCATGCATTC-3'; Rev: 5'-GACTCTAAGAAGGAGGACGTGG-3'. Acil restriction digest produces a 734bp band for the Rap1-WT allele and two bands at 636bp and 98bp for Rap1-I312R.

For mouse embryonic fibroblast (MEF) isolation, pregnant mice were sacrificed at E13.5 and embryos were harvested and dissected to remove limbs, liver and neural tissue. The remaining tissue was diced, treated with trypsin, and then cultured in serumcontaining media. Mouse embryonic stem cell (mESC) cultures were derived from the inner cell mass of preimplantation embryos.

\section{Plasmids}

Mouse Rap1 variants (wild type, Rap1-I312R) were cloned into the retroviral constructs pLPC-N-Flag-2xHA-MCS-Puro for ChIP-seq and pLPC-N-Flag-BirA*-13xGGGGS-MycMCS-Puro for proximity-based biotin labeling. For ColP, Rap1 variants (wild type, Rap1I312R, Rap1- $\Delta$ BRCT, Rap1- $\Delta M y b$, Rap1- $\Delta$ Coil Rap1- $\Delta R C T)$ were subcloned into the 
retroviral constructs pLPC-N-Myc-MCS, pLPC-N-Flag-MCS, and pcDNA-N-3xHA-MCS. Mouse Tip60, Epc1, Epc2, Dmap1, Ruvbl1, and Actl6a cloned into pCMV6-MCS-MycFlag were purchased from Origene and used for ColPs in Figure 3E-G. Mouse Tip60 and Epc1 variants (wild type, Epc1- $\triangle \mathrm{EPcA}, \mathrm{Epc1- \Delta EPcC,} \mathrm{Epc1-EPcA)} \mathrm{were} \mathrm{subcloned} \mathrm{by}$ restriction enzyme digest of PCR products from pCMV6-MCS-Myc-Flag into pLPC-NFlag-MCS and pLPC-N-Myc-MCS for ColPs in Figure 4B-E. Human RAP1 was expressed from pTriEx4 for protein affinity purification used in Figure 4G. For K48-linked ubiquitin ColP, pRK5-HA-Ubiquitin-K48 was a gift from Ted Dawson (Addgene, \#17605)

\section{Cell Culture}

Primary MEFs were cultured in $15 \%$ fetal bovine serum (FBS), 1x MEM Non-Essential Amino Acids (Gibco 11140050), $100 \mathrm{U} / \mathrm{mL}$ Pen/Strep (Gibco 15140122), 2mM Lglutamine (Gibco 25030149), and $50 \mu \mathrm{M}$ 2-mercaptoethanol in DMEM. SV40LTimmortalized MEFs were immortalized by retroviral infection with pBabeSV40LT (a gift from Greg Hannon) and cultured in 10\% bovine calf serum (BCS), 1x MEM Non-Essential Amino Acids (Gibco 11140050), 100 U/mL Pen/Strep (Gibco 15140122), and 2mM Lglutamine (Gibco 25030149) in DMEM. mESCs were grown on feeders or on gelatinized plates in 2i/LIF media composed of 15\% FBS, 1x NEAA, 100U/mL Pen/Strep, 2mM Lglutamine, 50 M 2-mercaptoethanol, 500 U/mL LIF Protein (Millipore Sigma ESG1106), $3 \mu \mathrm{M}$ CHIR99021/GSK-3 Inhibitor (Millipore Sigma 361571), and $1 \mu \mathrm{M}$ PD0325901/MEK1/2 Inhibitor (Millipore Sigma 444968) in DMEM. Cells were tested for mycoplasma using the LookOut mycoplasma PCR detection kit (Sigma MP0035), following the manufacturer's instructions and using the JumpStart Taq DNA polymerase 
(Sigma D9307). For proteasome inhibitor studies, cells were treated with 5uM MG132 (Invivogen TLRL-MG132) or with dimethyl sulfoxide (DMSO) as control.

\section{Western Blot Analysis}

Cells or tissues were either lysed directly in Laemmli buffer (Biorad 1610747) or in RIPA buffer $(25 \mathrm{mM}$ Tris $\mathrm{pH} 7.6,150 \mathrm{mM} \mathrm{NaCl}, 1 \% \mathrm{NP}-40,1 \%$ sodium deoxycholate, $0.1 \%$ SDS), sonicated to shear chromatin and spun at high-speed to pellet cellular debris. If lysed in RIPA, protein concentration was determined by BCA assay (Thermo Scientific 23225). Equal amounts of protein were separated by SDS-PAGE, transferred to nitrocellulose and probed with antibody. After incubation with secondary antibody (Millipore Sigma GENA931, mouse; GENA934, rabbit), immunoblots were developed with enhanced chemiluminescence (Biorad 1705060). Protein abundance was quantified by measuring the integrated intensity of bands using Fiji Image J and normalizing to loading controls. The following primary antibodies were used: mouse Rap1 (1252, rabbit polyclonal), TRF2 (Novus Biologicals NB110-57130), $\gamma$-tubulin (Millipore Sigma T6557, mouse monoclonal), $\alpha$-tubulin (Abcam ab7291, mouse monoclonal), histone H3 (Abcam ab1791, rabbit polyclonal), Flag (Cell Signaling \#14793, rabbit monoclonal), c-Myc (Santa Cruz Biotech. sc-789, rabbit polyclonal), HA (Abcam ab9110, rabbit polyclonal), and streptavidin-HRP (Invitrogen 1953050).

\section{IF-FISH}

MEFs and mESCs grown on coverslips were fixed with $4 \%$ paraformaldehyde for 10 min, washed with PBS, and permeabilized with $0.5 \%$ Triton X-100 buffer ( $0.5 \%$ Triton X-100, 
$20 \mathrm{mM}$ HEPES $\mathrm{pH} 7.9,50 \mathrm{mM} \mathrm{NaCl}, 3 \mathrm{mM} \mathrm{MgCl} 2,300 \mathrm{mM}$ sucrose. Cells were then incubated in blocking solution $(1 \mathrm{mg} / \mathrm{mL}$ BSA, $3 \%$ goat serum, $0.1 \%$ Triton $\mathrm{X}-100,1 \mathrm{mM}$ EDTA in PBS) at room temperature for $30 \mathrm{~min}$, followed by incubation with primary antibody diluted in blocking solution for 2 hours at room temperature. After washing with PBST (0.1\% Tween 20 in PBS) 3 times for 5 minutes each, cells were incubated with Alexa Fluor labeled secondary antibody (Thermo Fisher Scientific) for 45 minutes at room temperature. After washing with PBST 3 times for 5 minutes each, if FISH was performed, cells were dehydrated with ethanol series $(70 \%, 95 \%$, then $100 \%)$ and hybridized with TAMRA-OO-(TTAGGG)3 PNA probe (Applied Biosystems) in formamide hybridization solution ( $70 \%$ formamide, $0.5 \%$ blocking reagent (Roche), $10 \mathrm{mM}$ Tris- $\mathrm{HCl}, \mathrm{pH} 7.2)$ at $80^{\circ} \mathrm{C}$ for $5 \mathrm{~min}$. Cells were allowed to cool at room temperature for 2 hours, then washed 4 time for 10 minutes each with formamide washing solution (70\% formamide, $10 \mathrm{mM}$ Tris$\mathrm{HCl} \mathrm{pH} \mathrm{7.2).} \mathrm{Cells} \mathrm{were} \mathrm{then} \mathrm{washed} \mathrm{with} \mathrm{PBS} 3$ times for 5 min each, counterstained with DAPI, and coverslips were mounted on slides with anti-fade reagent (Prolong Gold, Invitrogen). Images were captured using a Nikon Eclipse Ti or DeltaVision microscope. The primary antibodies used: mouse Rap1 (1252, rabbit polyclonal), HA (Abcam ab9110, rabbit polyclonal), Flag M2 (Millipore Sigma F1804, mouse monoclonal), Alexa Fluor 488 streptavidin (Thermo Fisher Scientific S11223), and Zscan4 (Millipore Sigma AB4340).

\section{C::tdTomato reporter live-cell imaging}

The 2C::tdTomato reporter was a gift from Samuel Pfaff (Addgene \#40281). To establish stable cell lines, mESCs were transfected with the $2 \mathrm{C}:$ :tdTomato reporter followed by selection with hygromycin for 7 days to select for cells with stable integrations. Live-cell 
imaging and analysis was performed using Incucyte (Sartorius). The proportion of 2C::tdTomato positive cells was determined by normalizing the number of red objects to cell confluency as determined by phase contrast imaging.

\section{RNA-sequencing}

Cell pellets were submitted to Genewiz for RNA extraction, polyA library preparation, and high-throughput sequencing using their pipelines. For bioinformatic analysis of RNAsequencing (RNA-seq) data, the Seq-N-Slide workflow (source code available at: https://github.com/igordot/sns) was employed. Under this workflow, FASTQ files were trimmed using Trimmomatic (Bolger et al. 2014) to remove adapters and low quality bases and aligned to the mm10 reference genome using RNA-STAR (Dobin et al. 2013). Alignments to other species and common contaminants were removed by fastq_screen (source code available at: https://github.com/StevenWingett/FastQ-Screen). Genessamples counts matrices were generated using featureCounts (Liao et al. 2019). Differential gene expression analysis was performed by DESeq2 (Love et al. 2014). Differentially expressed genes (DEGs) were determined based on a fold-change (FC) > 1.5 and false discovery rate $(F D R)<0.1$. Hierarchically clustered heatmaps were generated using the ComplexHeatmaps package ( $\mathrm{Gu}$ et al. 2016). Kmeans clustering was performed using Morpheus (https://software.broadinstitute.org/morpheus).

Differential repeat expression analysis was performed as previously described (Ishiuchi et al. 2015). Trimmed RNA-seq reads were aligned to the reference genome using RNA-STAR (Dobin et al. 2013), allowing multimapping of reads. Nonuniquely mapped reads were mapped to the annotation of repeat sequences in the mouse genome 
using RepeatMasker (http://www.repeatmasker.org/). Differential gene expression analysis was performed by DESeq2 (Love et al. 2014). Differentially expressed repeats were determined based on a FC $>2$ and FDR $<0.1$. To quantify proportion of DEGs near MERVL MT_Mm sites, BEDtools (Quinlan and Hall 2010) window function was used to count the number of DEGs and total number of genes at increasing distances from MT2_Mm sites as annotated by RepeatMasker

\section{Chromatin Immunoprecipitation (ChIP)}

For Rap1 ChIP, SV40LT-immortalized Rap1\% MEFs were transduced with pLPC-Flag2xHA-EV, pLPC-Flag-2xHA-Rap1, and pLPC-Flag-2xHA-Rap1-I312R retrovirus produced from transfected Phoenix cells. $10^{8}$ cells were harvested by trypsinization, washed twice with PBS, and double-fixed with $2 \mathrm{mM}$ ethylene glycol bis (succinimidylsuccinate) (EGS, Thermo Fisher Scientific 21565) in PBS for 45 min at room temperature and then with $1 \%$ formaldehyde for $20 \mathrm{~min}$ at room temperature. The reaction was quenched with $125 \mathrm{mM}$ glycine and samples were spun $240 \times \mathrm{g}$ for 5 min at $4^{\circ} \mathrm{C}$. Pellets were washed 2 times with cold PBS, resuspended in 10mL cold lysis buffer 1 (100 mM HEPES-KOH, 140 mM NaCl, 1 mM EDTA, 10\% glycerol, 0.5\% NP-40, 0.25\% Triton $\mathrm{X}-100$, and protease inhibitor cocktail), and incubated rocking for $10 \mathrm{~min}$ at $4^{\circ} \mathrm{C}$. Samples were spun $950 \times \mathrm{g}$ for $2 \mathrm{~min}$ at $4^{\circ} \mathrm{C}$, pellets were resuspended in $10 \mathrm{~mL}$ cold lysis buffer 2 (200 mM NaCl, 1 mM EDTA, 0.5 mM EGTA 10 mM Tris-HCl, and protease inhibitor cocktail), and incubated rocking for $10 \mathrm{~min}$ at $4^{\circ} \mathrm{C}$. Samples were spun $1500 \mathrm{xg}$ for $2 \mathrm{~min}$ at $4^{\circ} \mathrm{C}$, pellets were resuspended in $3 \mathrm{~mL}$ cold lysis buffer 3 (1 mM EDTA, $0.5 \mathrm{mM}$ EGTA, $10 \mathrm{mM}$ Tris- $\mathrm{HCl}$ at $\mathrm{pH} 8,100 \mathrm{mM} \mathrm{NaCl}, 0.1 \%$ Na-Deoxycholate, 0.5\% N-lauroyl sarcosine, 
and protease inhibitor cocktail) and run through a G27 needle 10 times. Samples were sonicated 10 cycles $30 \mathrm{sec}$ on/30sec off in a Bioruptor Pico. After sonication, 1/10 volume of $10 \%$ Triton $\mathrm{X}-100$ was added and samples were spun $18,400 \times \mathrm{g}$ for $10 \mathrm{~min}$ at $4^{\circ} \mathrm{C}$. Supernatants were precleared with 300uL ChIP-grade Protein G magnetic beads (Cell Signaling Cat. 9006) and then incubated rotating overnight at 4C with $10 \mu \mathrm{g}$ anti-HA ChIPgrade antibody (Abcam ab9110). The following morning, 30ul ChIP-grade Protein G magnetic beads were added and samples were incubated at $4^{\circ} \mathrm{C}$ rotating for two hours. Beads were washed a total of 5 times with cold wash buffer $(50 \mathrm{mM}$ Hepes at $\mathrm{pH} 7.6,1$ mM EDTA, 0.7\% Na-Deoxycholate, 1\% NP-40, 0.5 M LiCl, and protease inhibitor cocktail) and 1 time with PBS. ChIP DNA was eluted in $250 \mu \mathrm{L}$ elution buffer $(0.5 \%$ SDS and 100 $\mathrm{mM} \mathrm{NaHCO} 3$ ) by incubating at room temperature for $15 \mathrm{~min}$ on a roller. A second elution was performed by adding $250 \mu \mathrm{L}$ elution buffer and incubating $65^{\circ} \mathrm{C}$ for 20 min mixing. Eluates were combined and reverse cross-linked by adding $20 \mu \mathrm{l} \mathrm{M} \mathrm{NaCl}$ and then incubated at $65 \mathrm{C}$ for 4 hours. Samples were then purified by phenol-chloroform-isoamyl alcohol followed by ethanol precipitation and resuspension in water.

For mESC histone marks, $30 \times 10^{6}$ cells were crosslinked in Fixation Buffer (1\% formaldehyde, 15mM NaCl, 0.15mM EDTA, 0.075mM EGTA, 10mM HEPES pH 7.6 in DMEM) for $10 \mathrm{~min}$ at room temperature, then quenched by addition of $0.125 \mathrm{M}$ glycine. Cells were then washed with PBS, harvested by scraping, and centrifuged $2500 \times \mathrm{g}$ for 5 $\min$ at $4^{\circ} \mathrm{C}$. Cell pellets were resuspended in $5 \mathrm{~mL}$ Lysis Buffer 1 (50mM HEPES pH 7.5, $140 \mathrm{mM} \mathrm{NaCl}, 1 \mathrm{mM}$ EDTA, 10\% Glycerol, 0.5\% NP40, 0.25\% Triton-X 100, 10mM Sodium Butyrate, 0.2mM PMSF, and protease/phosphatase inhibitor cocktail), incubated rocking at $4^{\circ} \mathrm{C}$ for $10 \mathrm{~min}$, then centrifuged $1350 \times \mathrm{g}$ for $5 \mathrm{~min}$ at $4^{\circ} \mathrm{C}$. Cell pellets were 
then resuspended in $5 \mathrm{~mL}$ Lysis Buffer $2(10 \mathrm{mM}$ Tris $\mathrm{pH} 8.0,200 \mathrm{mM} \mathrm{NaCl}, 1 \mathrm{mM}$ EDTA, 0.5mM EGTA, 10mM Sodium Butyrate, 0.2mM PMSF, and protease/phosphatase inhibitor cocktail), incubated rocking at room temperature for $10 \mathrm{~min}$, then centrifuged $1350 \mathrm{x} \mathrm{g}$ for $5 \mathrm{~min}$ at $4^{\circ} \mathrm{C}$. The resulting nuclear pellet was resuspended in $1.2 \mathrm{~mL}$ Lysis Buffer 3 (10mM Tris pH 7.5, 1mM EDTA, 0.5mM EGTA, 0.5\% N-lauroylsarcosine, 10mM Sodium Butyrate, 0.2mM PMSF, and protease/phosphatase inhibitor cocktail) and sonicated for 15 cycles (30 sec on/30 sec off). Sonicated chromatin was spun at high speed for $30 \mathrm{~min}$ at $4^{\circ} \mathrm{C}$ to pellet insoluble debris and supernatant were used for IP. Depending on antibody used, $100 \mu \mathrm{g}$ of chromatin was aliquoted to a tube, Lysis Buffer 3 was added to bring the volume to $200 \mu \mathrm{l}$, and then to $300 \mu \mathrm{l}$ by addition of $100 \mu \mathrm{l}$ of Incubation Buffer (3\% Triton-X 100, 0.3\% Sodium Deoxycholate, 15mM EDTA, 10mM Sodium Butyrate, 0.2mM PMSF, and protease/phosphatase inhibitor cocktail). $8 \mu \mathrm{g}$ of antibody (anti-acetyl-histone H4, Millipore Sigma 06-598; anti-acetyl-histone H2A.Z, Millipore Sigma Abe1363) was then added and tubes were rotated overnight at $4^{\circ} \mathrm{C}$. The next day, Dynabeads Protein A magnetic beads (Thermo Fisher Cat. 1001D) were added and incubated for 2 hours rotating at $4^{\circ} \mathrm{C}$. Beads were then washed 5 times with RIPA buffer (50mM HEPES pH 7.5, 0.7\% Sodium Deoxycholate, 1mM EDTA, 1\% NP40, $500 \mathrm{mM}$ Lithium Chloride, $10 \mathrm{mM}$ Sodium Butyrate, $0.2 \mathrm{mM}$ PMSF, and protease/phosphatase cocktail) and 1 time with $1 x \mathrm{TE}+50 \mathrm{mM} \mathrm{NaCl}$. Antibody/DNA complexes were then eluted by adding $125 \mu$ I Elution Buffer (50mM Tris pH 8.0, 10mM EDTA, $1 \%$ SDS) and incubating $20 \mathrm{~min}$ at $65^{\circ} \mathrm{C}$ shaking. The eluate was then moved to a new tube and crosslinks were reversed by incubating shaking at $65^{\circ} \mathrm{C}$ overnight. Then, 
$4 \mathrm{ul}$ of Proteinase $\mathrm{K}(20 \mathrm{mg} / \mathrm{mL})$ was added and tubes were incubated $2 \mathrm{hr}$ at $55^{\circ} \mathrm{C}$ shaking. ChIP DNA was then purified by QIAquick PCR Purification Kit.

\section{ChIP dot blot}

ChIP DNA was denatured at $95^{\circ} \mathrm{C}$ for $5 \mathrm{~min}$ and dot blotted onto Hybond nylon membranes in 2x SSC. Membranes were treated with $1.5 \mathrm{M} \mathrm{NaCl} / 0.5 \mathrm{~N} \mathrm{NaOH}$ for $10 \mathrm{~min}$, and with $1 \mathrm{M} \mathrm{NaCl} / 0.5 \mathrm{M}$ Tris- $\mathrm{HCl}, \mathrm{pH} 7.0$ for $10 \mathrm{~min}$. DNA was then crosslinked to the membrane using a Stratagene UV crosslinker. End-labeled Telomere probe was prepared by incubating (CCCTAA $)_{4}$ oligo with T4 PNK enzyme and ${ }^{32} \mathrm{P}$-gamma-ATP at $37^{\circ} \mathrm{C}$ for $45 \mathrm{~min}$. Probe was then filtered through a G-25 column and hybridized to the crosslinked membrane overnight at $55^{\circ} \mathrm{C}$. Membranes were washed 3 times in $2 x$ SSC for 5 min, exposed overnight to Phosphorlmager screen, and imaged on a Typhoon gel scanner. The quantification of DNA precipitated was performed by measuring integrated intensity using Fiji ImageJ and normalizing to input samples.

\section{ChIP-sequencing Library Prep, Sequencing, and Analysis}

Sequencing libraries were prepared using the NEBNext $₫$ Ultra ${ }^{\text {TM }}$ II DNA Library Prep Kit for Illumina (NEB Cat. E7645S). For HA-Rap1 ChIP, sequencing was performed on Illumina NextSeq 500 (SE 150 cycles). For histone marks in mESCs, sequencing was performed on Illumina NovaSeq 6000 (PE 100 cycles).

For bioinformatic analysis of ChIP-sequencing (ChIP-seq) data, the Seq-N-Slide workflow (source code available at: https://github.com/igordot/sns) was employed. Under this workflow, reads were aligned to the mm10 reference genome using Bowtie2 
(Langmead and Salzberg 2012), duplicate reads were removed using Sambamba (source code available at: https://github.com/biod/sambamba), and genome browser tracks representing ChIP-seq profiles were generated using IGV (Robinson et al. 2011). MACS2 (Zhang et al. 2008) was used for peak calling. Deeptools (Ramirez et al. 2016) was used to generate heatmaps and density plots.

For telomere binding analysis using high-throughput sequencing, FASTQ files were processed using grep to count the number of reads containing $\geq 3$ consecutive telomere repeats (TTAGGG/CCCGAA) and normalized to the total number of reads.

\section{qRT-PCR}

RNA was purified from cells using the NucleoSpin RNA Mini Kit (Macherey-Nagel. 740955.50). 1ug of RNA was reverse transcribed using the iScript gDNA Clear cDNA Synthesis Kit (BioRad 1725034) and cDNA libraries were diluted 1:5. RT-PCR was performed using ssoAdvanced SYBR Green Supermix (Cat. 1725270) on a Roche LightCycler 480 II. qPCR primers can be found in Supplementary Table S6.

\section{Subcellular Fractionation}

$1 \times 10^{7}$ cells were resuspended in $200 \mu \mathrm{L}$ Buffer A (10mM HEPES pH 7.9, $10 \mathrm{mM} \mathrm{KCl}$, $1.5 \mathrm{mM} \mathrm{MgCl}, 0.34 \mathrm{M}$ Sucrose, $10 \%$ Glycerol, $1 \mathrm{mM}$ DTT, $1 \mathrm{mM}$ PMSF, and protease inhibitor cocktail). After addition of $2 \mathrm{uL}$ of $10 \%$ Triton-X 100 , resuspension was incubated $8 \mathrm{~min}$ on ice. Samples were centrifuged $1300 \times \mathrm{g}$ for $5 \mathrm{~min}$ at $4^{\circ} \mathrm{C}$. Supernatants (S1) were clarified at $20,000 \times \mathrm{g}$ for $5 \mathrm{~min}$ at $4^{\circ} \mathrm{C}$ to yield cytoplasmic fraction (S2). The pellet washed once with Buffer A and then lysed in $100 \mu \mathrm{L}$ Buffer B (3mM EDTA, 0.2mM EGTA, 
1mM DTT, 1mM PMSF, and protease inhibitor cocktail) for $30 \mathrm{~min}$ at $4^{\circ} \mathrm{C}$. Samples were centrifuged $1700 \times \mathrm{g}$ for $5 \mathrm{~min}$ at $4^{\circ} \mathrm{C}$ and the supernatant was kept as the nucleoplasmid (S3) fraction and pellets were the chromatin bound fraction (P3). Chromatin was washed one time with Buffer B and then resuspended in Laemmli buffer, sonicated, and boiled for $10 \min$ at $70^{\circ} \mathrm{C}$.

\section{Nucleosome reconstitution}

The Widom 601 nucleosome positioning sequence was obtained from a plasmid containing 8 copies of the fragment, each flanked by the EcoRV restriction site (Armache et al. 2011). Wild-type Xenopus histone was expressed individually in E. coli cells, extracted from inclusion bodies, and purified by size exclusion and anion chromatography (Dyer et al. 2004b). Purified histones were lyophilized (Sentry, VirTis) and stored at -80C for further use. Nucleosomes reconstitutions were performed as described (Dyer et al. 2004a; Armache et al. 2011). Briefly, recombinant histone octamers were assembled by mixing equimolar amounts of each of the four histones and dialyzing against refolding buffer (10 mM Tris, pH 7.5, 2.0 M NaCl, 1 mM EDTA, 5 mM BME). Assembled octamers were purified by size exclusion chromatography (Superdex 200, GE healthcare) in refolding buffer. Then, histone octamers and purified Widom 601 DNA were combined and dialyzed overnight with salt gradient dialysis (Rapid Pump, Gilson). Finally, assembled nucleosomes were purified through ion-exchange chromatography (Resource Q, GE Healthcare). Purified nucleosomes were dialyzed into TCS buffer $(20 \mathrm{mM}$ Tris-HCl $\mathrm{pH}$ 7.5, $1 \mathrm{mM}$ EDTA, $1 \mathrm{mM}$ DTT), concentrated, and stored at $4^{\circ} \mathrm{C}$. 


\section{Proximity-based biotinylation (BiolD) and streptavidin pull-down}

SV40LT-immortalized Rap1\%- MEFs were transduced with pLPC-Flag-BirA*-13xGGGGSMyc-EV, pLPC-Flag-BirA*-13xGGGGS-Myc-Rap1, and pLPC-Flag-BirA*-13xGGGGSMyc-Rap1-I312R retrovirus produced from transfected Phoenix cells. Single-cell clones were isolated, and independent clonal cell lines were screened by IF to identify those that expressed at high levels. Cells grown in $15-\mathrm{cm}^{2}$ dishes to be $90 \%$ confluency at time of harvest were treated with biotin $(50 \mu \mathrm{M})$ for 20 hours followed by biotin free media for $1 \mathrm{hr}$. For each condition, $10 \times 10^{6}$ cells were harvested by trypsinization, lysed for $1 \mathrm{hr}$ rocking at $4^{\circ} \mathrm{C}$ in NP40 lysis buffer $(10 \mathrm{mM}$ Tris $\mathrm{pH} 7.4,10 \mathrm{mM} \mathrm{NaCl}, 3 \mathrm{mM} \mathrm{MgCl} 2,1 \mathrm{mM}$ PMSF, and protease inhibitor cocktail), and then centrifuged $3300 \times \mathrm{g} 10 \mathrm{~min}$ at $4^{\circ} \mathrm{C}$ to pellet nuclei. Nuclei were resuspended in 500ul SDS Lysis Buffer (50mM Tris pH 8.0, 1\% SDS, 10mM EDTA, 1mM PMSF, and protease inhibitor cocktail), incubated on ice for 10min, followed by boiling for $5 \mathrm{~min}$ at $95^{\circ} \mathrm{C}$. Samples were then sonicated for 10 cycles (30 sec on/30 sec off) and clarified by centrifuging $15,000 \times \mathrm{g}$ for $10 \mathrm{~min}$ at $4^{\circ} \mathrm{C}$. Lysates were clarified by centrifuging $15,000 \times \mathrm{g}$ for $10 \mathrm{~min}$ at $4^{\circ} \mathrm{C}$. $50 \mathrm{uL}$ MyOne Streptavidin Beads (Thermo Fisher 65001) were then added and incubated rotating at $4^{\circ} \mathrm{C}$ overnight. Beads were then washed 2 times with RIPA buffer, 2 times with $2 \mathrm{M}$ Urea in $10 \mathrm{mM}$ Tris $\mathrm{pH}$ 8.0, 2 more times with RIPA, and then 2 times with Buffer 4 (50mM Tris pH7.4, 50mM NaCl). Proteins were then eluted from magnetic beads into Laemmli Buffer $+2 \mathrm{mM}$ biotin by boiling $5 \mathrm{~min}$ at $95^{\circ} \mathrm{C}$. Eluates were used for Western blot, Silver stain (Thermo Fisher Scientific 24612), and mass spectrometry analysis as previously described (Pinzaru et al. 2020). 


\section{Coimmunoprecipitation (CoIP)}

HEK293T cells were cotransfected with the indicated plasmid constructs using polythelenimine (PEI). 48hr post-transfection, cells were harvested in cold PBS, washed once with PBS, and lysed for $15 \mathrm{~min}$ on ice in $500 \mu \mathrm{L}$ Lysis Buffer (50mM Tris-HCl pH 7.4, $150 \mathrm{mM} \mathrm{NaCl}, 1 \%$ Triton X-100, 0.05\% SDS, $1 \mathrm{mM}$ EDTA, $1 \mathrm{mM}$ DTT, $1 \mathrm{mM}$ PMSF, and protease inhibitor cocktail). Salt boost was performed by adding $25 \mu \mathrm{L} 5 \mathrm{M} \mathrm{NaCl}$ and incubating on ice additional $5 \mathrm{~min}$. Then, $500 \mu \mathrm{L}$ cold $\mathrm{H}_{2} \mathrm{O}$ was added and lysates were spun at max speed for $10 \mathrm{~min}$ to pellet debris. Antibody for epitope to be precipitated (antiFlag, Millipore Sigma F1804; anti-HA, BioLegend 901533; anti-c-Myc Millipore Sigma M4439) was added to supernatants and incubated for 3 hours rotating at $4^{\circ} \mathrm{C}$. Protein $\mathrm{G}$ Sepharose (Millipore Sigma Cat. GE17-0618-01) preblocked in 5\% BSA was added and incubated for 1 additional hour rotating at $4^{\circ} \mathrm{C}$. Beads were washed 4 times in Wash Buffer (50mM Tris-HCl pH 7.4, 150mM NaCl, 1\% Triton X-100, 0.1\% SDS) and proteins were eluted in Laemmli buffer by boiling at $95^{\circ} \mathrm{C}$ for $5 \mathrm{~min}$ for Western blot or with $3 \times$ Flag peptide $\left(150 \mu \mathrm{g} / \mathrm{ml}\right.$, Sigma) for $1 \mathrm{hr}$ at $4^{\circ} \mathrm{C}$ for HAT assay. For ColP of Rap 1 with K48-Ub, the protocol was the same as above except no salt boost was performed, TNE (10 mM Tris $\mathrm{pH} 7.8,1 \% \mathrm{NP}-40,0.15 \mathrm{M} \mathrm{NaCl}, 1 \mathrm{mM}$ EDTA, and protease inhibitor cocktail) was used as lysis and wash buffer, and 4 mM N-ethylmaleimide (Sigma Cat. E3876) and 4 mM 1,10-phenanthroline (Sigma Cat. 131377) were included in the buffers. For DNase sensitivity assays, lysis buffer did not include EDTA or DTT. Lysates were supplemented with $\mathrm{MgCl} 2(2.5 \mathrm{mM})$ and incubated with DNase $(10 \mu \mathrm{g} / \mathrm{mL})$ for $1 \mathrm{hr}$ at RT. DNase was then inactivated by addition of EDTA and DTT before addition of antibody for IP. 


\section{Affinity purification of Rap1 protein}

Recombinant Rap1 with N-terminal His6-tags was expressed from the pTriEx4 vector in BL21(DE3) RIPL bacterial cells as described elsewhere (Vizlin-Hodzic et al. 2009; Nora et al. 2010). After 3-hour long induction of protein expression with 0.5mM isopropyl $\beta$-Dthiogalactoside, cells were harvested and resuspended in lysis buffer (50 mM sodium phosphate, $300 \mathrm{mM} \mathrm{NaCl}, 10 \mathrm{mM}$ imidazole, 10\% glycerol, and 0.5\% Tween 20, pH 8.0) containing protease inhibitor cocktail (Roche). Sonicated cell extracts were cleared by centrifugation and subsequently filtered (0.45 $\mu \mathrm{m}$ SterivexTM filter, Millipore). The supernatant containing Rap1 was further purified by Immobilized Metal ion Affinity Chromatography using TALON Metal Affinity Resin (Clontech) containing Co2+ cations as described (Yanez et al. 2005). Rap1 containing fractions were eluted in $200 \mathrm{mM}$ imidazole. For $\mathrm{His}_{6}$-tag removal, samples were digested by thrombin protease and purified using gel filtration chromatography to remove cleaved tags and residual protease.

The fractions containing pure protein were dialyzed into buffer composed of $50 \mathrm{mM}$ sodium phosphate with $50 \mathrm{mM} \mathrm{NaCl}(\mathrm{pH}$ 7.0) and, subsequently, proteins were concentrated by ultrafiltration (Amicon 30K, Millipore). The concentration of purified proteins was determined using the Bradford assay and purity was verified by electrophoresis in sodium dodecyl sulfate (SDS)-polyacrylamide gel which was subsequently stained using Bio-Safe Coomassie G 250 (Bio-Rad).

\section{Electrophoretic mobility shift assay (EMSA)}

Increasing amounts of 6xHis-tagged Rap1 (0 to $15 \mu \mathrm{M}$ ) or tag-free Rap1 proteins (0 to 15 $\mu \mathrm{M})$ were incubated with $100 \mathrm{nM}$ DNA (74bp long telomeric or 601 sequence) or 
nucleosome substrate in EMSA buffer (10 mM Tris pH 7.5, $100 \mathrm{mM} \mathrm{NaCl,} \mathrm{2.5 \%} \mathrm{Glycerol}$ and $1 \mathrm{mM} \mathrm{DTT}$ ) at room temperature for $30 \mathrm{~min}$. The binding reactions were resolved on native polyacrylamide gels (6\% PAGE, $0.25 \times$ TBE). Runs were performed in the cold room $\left(4^{\circ} \mathrm{C}\right)$ at $170 \mathrm{~V}$ for 1.5 hour, gels were stained with ethidium bromide and visualized on a Typhoon Trio+ scanner (Molecular Dynamics). Purified nucleosome substrates were a generous gift from Dr. Karim-Jean Armache.

\section{Histone acetyltransferase (HAT) assays}

Core histones and short oligonucleosome substrates for HAT assays were purified as previously described (Cote et al. 1995). Indicated substrates were incubated in a $15 \mu l$ reaction containing 50mM Tris- $\mathrm{HCl}$ pH8.0, 10\% glycerol, 1mM EDTA, 1mM DTT, 1mM PMSF, $10 \mathrm{mM}$ sodium butyrate and $0.125 \mu \mathrm{Ci}$ of [3H]-labeled Acetyl-CoA (Perkin Elmer). Samples were then spotted on phosphocellulose paper (St Vincent's Institute) and counts per minute (CPM) were quantified using Beckman Coulter LS6500 Multipurpose Scintillation Counter.

\section{Tandem affinity purification (TAP) of native TIP60/p400 complex for HAT assays}

Native TIP60/p400 complex was affinity purified as previously described (Dalvai et al. 2015). Briefly, nuclear extracts (Abmayr et al. 2006) were prepared from $1 \times 10^{9}-3 \times$ $10^{9} \mathrm{~K} 562$ cells expressing EPC1-3xFLAG-2xStrep from the AAVS1 locus (empty vector for Mock preparations). Tween-20 was added to $0.1 \%$, and extracts were centrifuged 17,000 rpm in Beckman JA-20 rotor for $1 \mathrm{~h}$ at $4 \mathrm{C}$. After preclearing with 300ul Sepharose CL-6B (Sigma), extracts were incubated with 250uL anti-Flag M2 affinity 
resin (Sigma) for 2 hours at 4C. Beads were then washed in Poly-Prep columns (BioRad) with 40 column volumes of Buffer 1 (20 mM HEPES-KOH pH 7.9, 10\% glycerol, $300 \mathrm{mM} \mathrm{KCl}, 0.1 \%$ Tween 20, $1 \mathrm{mM}$ DTT, Halt protease and phosphatase inhibitor cocktail without EDTA (Pierce)), followed by 40 column volumes Buffer 2 (20 mM HEPES$\mathrm{KOH} \mathrm{pH} \mathrm{7.9,10 \%} \mathrm{glycerol,} 150 \mathrm{mM} \mathrm{KCl,} \mathrm{0.1 \%} \mathrm{Tween} \mathrm{20,} 1$ mM DTT, Halt protease and phosphatase inhibitor cocktail without EDTA (Pierce)). Protein complexes were eluted with 3xFlag peptide (200ug/mL, Sigma) in 5 column volumes Buffer 2 for 1 hour at 4C. The eluted fraction was then mixed with 125ul Strep-Tactin Sepharose (IBA) affinity matrix for $1 \mathrm{hr}$ at $4^{\circ} \mathrm{C}$. Beads were then washed again in in Poly-Prep columns (Bio-Rad) with 40 column volumes of Buffer 2. Complexes were then eluted in two fractions with 2.5mM D-biotin in 4 column volumes Buffer 2 and flash frozen in liquid nitrogen.

\section{siRNA Transfection}

For mESCs, 75,000 cells were reverse transfected into gelatin-coated 24-well plates using Lipofectamine RNAiMAX (Thermo Fisher Scientific Cat. 13778100) according to the manufacturer's instructions and a final concentration of 30nM for each siRNA. 48hr post-transfection, RNA was purified from cells using the NucleoSpin RNA Mini Kit (Macherey-Nagel Cat. 740955.50). A list of siRNAs used in this study can be found in Supplementary Table S7.

\section{RAP1-EPC1 interaction in vitro}

1ug of soluble His-Rap1 was pre-cleared on Glutathione sepharose 4B beads (GE Healthcare) for $1 \mathrm{~h}$ at $4 \mathrm{C}$, then incubated with either $3 \mu \mathrm{g}$ (measured by Bradford protein 
assay) of GST-tagged EPC1 (aa 1-581) or GST alone immobilized on Glutathione sepharose beads for $2 \mathrm{~h} 30 \mathrm{~min}$ at $4 \mathrm{C}$ in $200 \mathrm{uL}$ Pulldown Buffer [200mM NaCl, $25 \mathrm{mM}$ Hepes pH 7.5, $10 \%$ glycerol, $100 \mu \mathrm{g} / \mathrm{mL}$ BSA, 1 mM PMSF, $0.5 \mathrm{mM}$ DTT, $0.1 \%$ Tween20, $2 \mu \mathrm{g} / \mathrm{mL}$ leupeptin, $2 \mu \mathrm{g} / \mathrm{mL}$ pepstatin, $5 \mu \mathrm{g} / \mathrm{mL}$ aprotinin]. Beads were washed twice with Pulldown Buffer and ran on SDS-PAGE followed by western blotting (anti-His Clontech 631212). 


\section{References}

Abmayr SM, Yao T, Parmely T, Workman JL. 2006. Preparation of nuclear and cytoplasmic extracts from mammalian cells. Curr Protoc Mol Biol Chapter 12: Unit 1211.

Acharya D, Hainer SJ, Yoon Y, Wang F, Bach I, Rivera-Perez JA, Fazzio TG. 2017. KAT-Independent Gene Regulation by Tip60 Promotes ESC Self-Renewal but Not Pluripotency. Cell Rep 19: 671-679.

Allard S, Utley RT, Savard J, Clarke A, Grant P, Brandl CJ, Pillus L, Workman JL, Cote J. 1999. NuA4, an essential transcription adaptor/histone $\mathrm{H} 4$ acetyltransferase complex containing Esa1p and the ATM-related cofactor Tra1p. EMBO J 18: 5108-5119.

Arat NO, Griffith JD. 2012. Human Rap1 interacts directly with telomeric DNA and regulates TRF2 localization at the telomere. J Biol Chem 287: 41583-41594.

Armache KJ, Garlick JD, Canzio D, Narlikar GJ, Kingston RE. 2011. Structural basis of silencing: Sir3 BAH domain in complex with a nucleosome at 3.0 A resolution. Science 334: 977-982.

Auger A, Galarneau L, Altaf M, Nourani A, Doyon Y, Utley RT, Cronier D, Allard S, Cote J. 2008. Eaf1 is the platform for NuA4 molecular assembly that evolutionarily links chromatin acetylation to ATP-dependent exchange of histone H2A variants. Mol Cell Biol 28: 22572270.

Berman J, Tachibana CY, Tye BK. 1986. Identification of a telomere-binding activity from yeast. Proc Natl Acad Sci U S A 83: 3713-3717.

Bolger AM, Lohse M, Usadel B. 2014. Trimmomatic: a flexible trimmer for Illumina sequence data. Bioinformatics 30: 2114-2120.

Boudreault AA, Cronier D, Selleck W, Lacoste N, Utley RT, Allard S, Savard J, Lane WS, Tan S, Cote J. 2003. Yeast enhancer of polycomb defines global Esa1-dependent acetylation of chromatin. Genes Dev 17: 1415-1428.

Bram RJ, Kornberg RD. 1985. Specific protein binding to far upstream activating sequences in polymerase II promoters. Proc Natl Acad Sci U S A 82: 43-47.

Buchman AR, Kimmerly WJ, Rine J, Kornberg RD. 1988a. Two DNA-binding factors recognize specific sequences at silencers, upstream activating sequences, autonomously replicating sequences, and telomeres in Saccharomyces cerevisiae. Mol Cell Biol 8: 210-225.

Buchman AR, Lue NF, Kornberg RD. 1988b. Connections between transcriptional activators, silencers, and telomeres as revealed by functional analysis of a yeast DNA-binding protein. Mol Cell Biol 8: 5086-5099.

Celli GB, de Lange T. 2005. DNA processing is not required for ATM-mediated telomere damage response after TRF2 deletion. Nat Cell Biol 7: 712-718.

Chambers A, Tsang JS, Stanway C, Kingsman AJ, Kingsman SM. 1989. Transcriptional control of the Saccharomyces cerevisiae PGK gene by RAP1. Mol Cell Biol 9: 5516-5524.

Chen F, Zhang W, Xie D, Gao T, Dong Z, Lu X. 2020. Histone chaperone FACT represses retrotransposon MERVL and MERVL-derived cryptic promoters. Nucleic Acids Res 48: 10211-10225.

Chen PB, Hung JH, Hickman TL, Coles AH, Carey JF, Weng Z, Chu F, Fazzio TG. 2013. Hdac6 regulates Tip60-p400 function in stem cells. Elife 2: e01557. 
Chen Y, Rai R, Zhou ZR, Kanoh J, Ribeyre C, Yang Y, Zheng H, Damay P, Wang F, Tsujii H et al. 2011. A conserved motif within RAP1 has diversified roles in telomere protection and regulation in different organisms. Nat Struct Mol Biol 18: 213-221.

Chiang YJ, Kim SH, Tessarollo L, Campisi J, Hodes RJ. 2004. Telomere-associated protein TIN2 is essential for early embryonic development through a telomerase-independent pathway. Mol Cell Biol 24: 6631-6634.

Chittuluru JR, Chaban Y, Monnet-Saksouk J, Carrozza MJ, Sapountzi V, Selleck W, Huang J, Utley RT, Cramet M, Allard S et al. 2011. Structure and nucleosome interaction of the yeast NuA4 and Piccolo-NuA4 histone acetyltransferase complexes. Nat Struct Mol Biol 18: 1196-1203.

Cote J, Utley R, Workman J. 1995. Basic analysis of transcription factor binding to nucleosomes. in Methods in Molecular Genetics (ed. K Adolph), pp. 108-128. Academic Press.

Dalvai M, Loehr J, Jacquet K, Huard CC, Roques C, Herst P, Cote J, Doyon Y. 2015. A Scalable Genome-Editing-Based Approach for Mapping Multiprotein Complexes in Human Cells. Cell Rep 13: 621-633.

de Lange T. 2005. Shelterin: the protein complex that shapes and safeguards human telomeres. Genes Dev 19: 2100-2110.

Dobin A, Davis CA, Schlesinger F, Drenkow J, Zaleski C, Jha S, Batut P, Chaisson M, Gingeras TR. 2013. STAR: ultrafast universal RNA-seq aligner. Bioinformatics 29: 15-21.

Doyon Y, Cote J. 2004. The highly conserved and multifunctional NuA4 HAT complex. Curr Opin Genet Dev 14: 147-154.

Doyon Y, Selleck W, Lane WS, Tan S, Cote J. 2004. Structural and functional conservation of the NuA4 histone acetyltransferase complex from yeast to humans. Mol Cell Biol 24: 18841896.

Dyer PN, Edayathumangalam RS, White CL, Bao Y, Chakravarthy S, Muthurajan UM, Luger K. 2004a. Reconstitution of nucleosome core particles from recombinant histones and DNA. Methods Enzymol 375: 23-44.

Dyer PN, Edayathumangalam RS, White CL, Bao YH, Chakravarthy S, Muthurajan UM, Luger K. 2004b. Reconstitution of nucleosome core particles from recombinant histones and DNA. Chromatin and Chromatin Remodeling Enzymes, Pt A 375: 23-44.

Fazzio TG, Huff JT, Panning B. 2008. An RNAi screen of chromatin proteins identifies Tip60-p400 as a regulator of embryonic stem cell identity. Cell 134: 162-174.

Fu X, Djekidel MN, Zhang Y. 2020. A transcriptional roadmap for 2C-like-to-pluripotent state transition. Sci Adv 6: eaay5181.

Fu X, Wu X, Djekidel MN, Zhang Y. 2019. Myc and Dnmt1 impede the pluripotent to totipotent state transition in embryonic stem cells. Nat Cell Biol 21: 835-844.

Go CD, Knight JDR, Rajasekharan A, Rathod B, Hesketh GG, Abe KT, Youn JY, Samavarchi-Tehrani $\mathrm{P}$, Zhang $\mathrm{H}$, Zhu LY et al. 2021. A proximity-dependent biotinylation map of a human cell. Nature 595: 120-124.

Hanaoka S, Nagadoi A, Yoshimura S, Aimoto S, Li B, de Lange T, Nishimura Y. 2001. NMR structure of the hRap1 Myb motif reveals a canonical three-helix bundle lacking the positive surface charge typical of Myb DNA-binding domains. J Mol Biol 312: 167-175.

Hockemeyer D, Daniels JP, Takai H, de Lange T. 2006. Recent expansion of the telomeric complex in rodents: Two distinct POT1 proteins protect mouse telomeres. Cell 126: 63-77. 
Huet J, Cottrelle P, Cool M, Vignais ML, Thiele D, Marck C, Buhler JM, Sentenac A, Fromageot P. 1985. A general upstream binding factor for genes of the yeast translational apparatus. EMBO J 4: 3539-3547.

Huet J, Sentenac A. 1987. TUF, the yeast DNA-binding factor specific for UASrpg upstream activating sequences: identification of the protein and its DNA-binding domain. Proc Natl Acad Sci U S A 84: 3648-3652.

Iglesias N, Redon S, Pfeiffer V, Dees M, Lingner J, Luke B. 2011. Subtelomeric repetitive elements determine TERRA regulation by Rap1/Rif and Rap1/Sir complexes in yeast. EMBO Rep 12: 587-593.

Ishiuchi T, Enriquez-Gasca R, Mizutani E, Boskovic A, Ziegler-Birling C, Rodriguez-Terrones D, Wakayama T, Vaquerizas JM, Torres-Padilla ME. 2015. Early embryonic-like cells are induced by downregulating replication-dependent chromatin assembly. Nat Struct Mol Biol 22: 662-671.

Jacquet K, Fradet-Turcotte A, Avvakumov N, Lambert JP, Roques C, Pandita RK, Paquet E, Herst P, Gingras AC, Pandita TK et al. 2016. The TIP60 Complex Regulates Bivalent Chromatin Recognition by 53BP1 through Direct H4K20me Binding and H2AK15 Acetylation. Mol Cell 62: 409-421.

Kabir S, Hockemeyer D, de Lange T. 2014. TALEN gene knockouts reveal no requirement for the conserved human shelterin protein Rap1 in telomere protection and length regulation. Cell Rep 9: 1273-1280.

Kanoh J, Ishikawa F. 2001. spRap1 and spRif1, recruited to telomeres by Taz1, are essential for telomere function in fission yeast. Curr Biol 11: 1624-1630.

Karlseder J, Kachatrian L, Takai H, Mercer K, Hingorani S, Jacks T, de Lange T. 2003. Targeted deletion reveals an essential function for the telomere length regulator Trf1. Mol Cell Biol 23: 6533-6541.

Kibe T, Osawa GA, Keegan CE, de Lange T. 2010. Telomere protection by TPP1 is mediated by POT1a and POT1b. Mol Cell Biol 30: 1059-1066.

Kyrion G, Liu K, Liu C, Lustig AJ. 1993. RAP1 and telomere structure regulate telomere position effects in Saccharomyces cerevisiae. Genes Dev 7: 1146-1159.

Langmead B, Salzberg SL. 2012. Fast gapped-read alignment with Bowtie 2. Nat Methods 9: 357359.

Lazzerini-Denchi E, Sfeir A. 2016. Stop pulling my strings - what telomeres taught us about the DNA damage response. Nat Rev Mol Cell Biol 17: 364-378.

Li B, Oestreich S, de Lange T. 2000. Identification of human Rap1: implications for telomere evolution. Cell 101: 471-483.

Liao Y, Smyth GK, Shi W. 2019. The R package Rsubread is easier, faster, cheaper and better for alignment and quantification of RNA sequencing reads. Nucleic Acids Res 47: e47.

Longtine MS, Wilson NM, Petracek ME, Berman J. 1989. A yeast telomere binding activity binds to two related telomere sequence motifs and is indistinguishable from RAP1. Curr Genet 16: 225-239.

Lototska L, Yue JX, Li J, Giraud-Panis MJ, Songyang Z, Royle NJ, Liti G, Ye J, Gilson E, MendezBermudez A. 2020. Human RAP1 specifically protects telomeres of senescent cells from DNA damage. EMBO Rep 21: e49076. 
Love MI, Huber W, Anders S. 2014. Moderated estimation of fold change and dispersion for RNAseq data with DESeq2. Genome Biol 15: 550.

Lustig AJ, Kurtz S, Shore D. 1990. Involvement of the silencer and UAS binding protein RAP1 in regulation of telomere length. Science 250: 549-553.

Macfarlan TS, Gifford WD, Driscoll S, Lettieri K, Rowe HM, Bonanomi D, Firth A, Singer O, Trono D, Pfaff SL. 2012. Embryonic stem cell potency fluctuates with endogenous retrovirus activity. Nature 487: 57-63.

Marion RM, Montero JJ, Lopez de Silanes I, Grana-Castro O, Martinez P, Schoeftner S, PalaciosFabrega JA, Blasco MA. 2019. TERRA regulate the transcriptional landscape of pluripotent cells through TRF1-dependent recruitment of PRC2. Elife 8.

Markiewicz-Potoczny M, Lobanova A, Loeb AM, Kirak O, Olbrich T, Ruiz S, Lazzerini Denchi E. 2021. TRF2-mediated telomere protection is dispensable in pluripotent stem cells. Nature 589: 110-115.

Martinez P, Gomez-Lopez G, Garcia F, Mercken E, Mitchell S, Flores JM, de Cabo R, Blasco MA. 2013. RAP1 protects from obesity through its extratelomeric role regulating gene expression. Cell Rep 3: 2059-2074.

Martinez P, Gomez-Lopez G, Pisano DG, Flores JM, Blasco MA. 2016. A genetic interaction between RAP1 and telomerase reveals an unanticipated role for RAP1 in telomere maintenance. Aging Cell 15: 1113-1125.

Martinez P, Thanasoula M, Carlos AR, Gomez-Lopez G, Tejera AM, Schoeftner S, Dominguez O, Pisano DG, Tarsounas M, Blasco MA. 2010. Mammalian Rap1 controls telomere function and gene expression through binding to telomeric and extratelomeric sites. Nat Cell Biol 12: 768-780.

Nanavaty V, Sandhu R, Jehi SE, Pandya UM, Li B. 2017. Trypanosoma brucei RAP1 maintains telomere and subtelomere integrity by suppressing TERRA and telomeric RNA:DNA hybrids. Nucleic Acids Res 45: 5785-5796.

Nora GJ, Buncher NA, Opresko PL. 2010. Telomeric protein TRF2 protects Holliday junctions with telomeric arms from displacement by the Werner syndrome helicase. Nucleic Acids Res 38: 3984-3998.

Pardo B, Marcand S. 2005. Rap1 prevents telomere fusions by nonhomologous end joining. EMBO J 24: 3117-3127.

Paul NK, Baksh KA, Arias JF, Zamble DB. 2020. The impact of a His-tag on DNA binding by RNA polymerase alpha-C-terminal domain from Helicobacter pylori. Protein Expr Purif 167: 105541.

Pinzaru AM, Kareh M, Lamm N, Lazzerini-Denchi E, Cesare AJ, Sfeir A. 2020. Replication stress conferred by POT1 dysfunction promotes telomere relocalization to the nuclear pore. Genes Dev 34: 1619-1636.

Platt JM, Ryvkin P, Wanat JJ, Donahue G, Ricketts MD, Barrett SP, Waters HJ, Song S, Chavez A, Abdallah KO et al. 2013. Rap1 relocalization contributes to the chromatin-mediated gene expression profile and pace of cell senescence. Genes Dev 27: 1406-1420.

Pradhan SK, Su T, Yen L, Jacquet K, Huang C, Cote J, Kurdistani SK, Carey MF. 2016. EP400 Deposits H3.3 into Promoters and Enhancers during Gene Activation. Mol Cell 61: 27-38.

Quinlan AR, Hall IM. 2010. BEDTools: a flexible suite of utilities for comparing genomic features. Bioinformatics 26: 841-842. 
Rai R, Chen Y, Lei M, Chang S. 2016. TRF2-RAP1 is required to protect telomeres from engaging in homologous recombination-mediated deletions and fusions. Nat Commun 7: 10881.

Ramirez F, Ryan DP, Gruning B, Bhardwaj V, Kilpert F, Richter AS, Heyne S, Dundar F, Manke T. 2016. deepTools2: a next generation web server for deep-sequencing data analysis. Nucleic Acids Res 44: W160-165.

Robinson JT, Thorvaldsdottir H, Winckler W, Guttman M, Lander ES, Getz G, Mesirov JP. 2011. Integrative genomics viewer. Nat Biotechnol 29: 24-26.

Rodriguez-Terrones D, Gaume X, Ishiuchi T, Weiss A, Kopp A, Kruse K, Penning A, Vaquerizas JM, Brino L, Torres-Padilla ME. 2018. A molecular roadmap for the emergence of earlyembryonic-like cells in culture. Nat Genet 50: 106-119.

Roux KJ, Kim DI, Raida M, Burke B. 2012. A promiscuous biotin ligase fusion protein identifies proximal and interacting proteins in mammalian cells. J Cell Biol 196: 801-810.

Sapountzi V, Cote J. 2011. MYST-family histone acetyltransferases: beyond chromatin. Cell Mol Life Sci 68: 1147-1156.

Sarthy J, Bae NS, Scrafford J, Baumann P. 2009. Human RAP1 inhibits non-homologous end joining at telomeres. EMBO J 28: 3390-3399.

Selleck W, Fortin I, Sermwittayawong D, Cote J, Tan S. 2005. The Saccharomyces cerevisiae Piccolo NuA4 histone acetyltransferase complex requires the Enhancer of Polycomb A domain and chromodomain to acetylate nucleosomes. Mol Cell Biol 25: 5535-5542.

Setiaputra D, Ahmad S, Dalwadi U, Steunou AL, Lu S, Ross JD, Dong MQ, Cote J, Yip CK. 2018. Molecular Architecture of the Essential Yeast Histone Acetyltransferase Complex NuA4 Redefines Its Multimodularity. Mol Cell Biol 38.

Sfeir A, Kabir S, van Overbeek M, Celli GB, de Lange T. 2010. Loss of Rap1 induces telomere recombination in the absence of NHEJ or a DNA damage signal. Science 327: 1657-1661.

Sheikh BN, Akhtar A. 2019. The many lives of KATs - detectors, integrators and modulators of the cellular environment. Nat Rev Genet 20: 7-23.

Shore D, Nasmyth K. 1987. Purification and cloning of a DNA binding protein from yeast that binds to both silencer and activator elements. Cell 51: 721-732.

Shore D, Stillman DJ, Brand AH, Nasmyth KA. 1987. Identification of silencer binding proteins from yeast: possible roles in SIR control and DNA replication. EMBO J 6: 461-467.

Song S, Perez JV, Svitko W, Ricketts MD, Dean E, Schultz D, Marmorstein R, Johnson FB. 2020. Rap1-mediated nucleosome displacement can regulate gene expression in senescent cells without impacting the pace of senescence. Aging Cell 19: e13061.

Steunou AL, Rossetto D, Cote J. 2014. Regulating Chromatin by Histone Acetylation. in Fundamentals of Chromatin (eds. JL Workman, SM Abmayr), pp. 147-212. Springer, New York.

Teo H, Ghosh S, Luesch H, Ghosh A, Wong ET, Malik N, Orth A, de Jesus P, Perry AS, Oliver JD et al. 2010. Telomere-independent Rap1 is an IKK adaptor and regulates NF-kappaBdependent gene expression. Nat Cell Biol 12: 758-767.

Vignais ML, Woudt LP, Wassenaar GM, Mager WH, Sentenac A, Planta RJ. 1987. Specific binding of TUF factor to upstream activation sites of yeast ribosomal protein genes. EMBO J 6: 1451-1457. 
Vizlin-Hodzic D, Ryme J, Simonsson S, Simonsson T. 2009. Developmental studies of Xenopus shelterin complexes: the message to reset telomere length is already present in the egg. FASEB J 23: 2587-2594.

Workman JL, Abmayr SM. 2014. Fundamentals of chromatin. Springer, New York.

Xu P, Li C, Chen Z, Jiang S, Fan S, Wang J, Dai J, Zhu P, Chen Z. 2016. The NuA4 Core Complex Acetylates Nucleosomal Histone H4 through a Double Recognition Mechanism. Mol Cell 63: 965-975.

Yanez GH, Khan SJ, Locovei AM, Pedroso IM, Fletcher TM. 2005. DNA structure-dependent recruitment of telomeric proteins to single-stranded/double-stranded DNA junctions. Biochem Biophys Res Commun 328: 49-56.

Yang D, Xiong Y, Kim H, He Q, Li Y, Chen R, Songyang Z. 2011. Human telomeric proteins occupy selective interstitial sites. Cell Res 21: 1013-1027.

Yang X, Figueiredo LM, Espinal A, Okubo E, Li B. 2009. RAP1 is essential for silencing telomeric variant surface glycoprotein genes in Trypanosoma brucei. Cell 137: 99-109.

Yeung F, Ramirez CM, Mateos-Gomez PA, Pinzaru A, Ceccarini G, Kabir S, Fernandez-Hernando C, Sfeir A. 2013. Nontelomeric role for Rap1 in regulating metabolism and protecting against obesity. Cell Rep 3: 1847-1856.

Zhang W, Chen F, Chen R, Xie D, Yang J, Zhao X, Guo R, Zhang Y, Shen Y, Goke J et al. 2019. Zscan4c activates endogenous retrovirus MERVL and cleavage embryo genes. Nucleic Acids Res 47: 8485-8501.

Zhang Y, Liu T, Meyer CA, Eeckhoute J, Johnson DS, Bernstein BE, Nusbaum C, Myers RM, Brown M, Li W et al. 2008. Model-based analysis of ChIP-Seq (MACS). Genome Biol 9: R137. 